\title{
Global transcriptomic analysis of an engineered Escherichia coli strain lacking the phosphoenolpyruvate: carbohydrate phosphotransferase system during shikimic acid production in rich culture medium
}

Larisa Cortés-Tolalpa', Rosa María Gutiérrez-Ríos², Luz María Martínez, Ramón de Anda', Guillermo Gosset', Francisco Bolívar ${ }^{1}$ and Adelfo Escalante ${ }^{1 *}$

\begin{abstract}
Background: Efficient production of SA in Escherichia coli has been achieved by modifying key genes of the central carbon metabolism and SA pathway, resulting in overproducing strains grown in batch-or fed-batch-fermentor cultures using a complex broth including glucose and YE. In this study, we performed a GTA to identify those genes significantly upregulated in an engineered E. coli strain, PB12.SA22, in mid EXP (5 h), early STA (STA1, 9 h), and late STA (STA2, 44 h) phases, grown in complex fermentation broth in batch-fermentor cultures.

Results: Growth of E. coli PB12.SA22 in complex fermentation broth for SA production resulted in an EXP growth during the first $9 \mathrm{~h}$ of cultivation depending of supernatant available aromatic amino acids provided by YE because, when tryptophan was totally consumed, cells entered into a second, low-growth phase (even in the presence of glucose) until $26 \mathrm{~h}$ of cultivation. At this point, glucose was completely consumed but SA production continued until the end of the fermentation ( $50 \mathrm{~h}$ ) achieving the highest accumulation (7.63 g/L of SA). GTA between EXP/ STA1, EXP/STA2 and STA1/STA2 comparisons showed no significant differences in the regulation of genes encoding enzymes of central carbon metabolism as in SA pathway, but those genes encoding enzymes involved in sugar, amino acid, nucleotide/nucleoside, iron and sulfur transport; amino acid catabolism and biosynthesis; nucleotide/ nucleoside salvage; acid stress response and modification of IM and OM were upregulated between comparisons.

Conclusions: GTA during SA production in batch-fermentor cultures of strain PB12.SA22 grown in complex fermentation broth during the EXP, STA1 and STA2 phases was studied. Significantly, upregulated genes during the EXP and STA1 phases were associated with transport, amino acid catabolism, biosynthesis, and nucleotide/ nucleoside salvage. In STA2, upregulation of genes encoding transporters and enzymes involved in the synthesis and catabolism of Arg suggests that this amino acid could have a key role in the fuelling of carbon toward SA synthesis, whereas upregulation of genes involved in $\mathrm{pH}$ stress response, such as membrane modifications, suggests a possible response to environmental conditions imposed on the cell at the end of the fermentation.
\end{abstract}

Keywords: Shikimic acid production, Escherichia coli PTS- strain, Batch-fermentor culture, Complex fermentation broth, Global transcriptomic analysis, Microarrays, Regulatory network

\footnotetext{
*Correspondence: adelfo@ibt.unam.mx

'Departamento de Ingeniería Celular y Biocatálisis, Instituto de Biotecnología,

Universidad Nacional Autónoma de México, Av. Universidad 2001, Col.

Chamilpa, Cuernavaca, Morelos 62210, México

Full list of author information is available at the end of the article
}

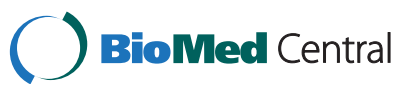

(c) 2014 Cortés-Tolalpa et al.; licensee BioMed Central Ltd. This is an Open Access article distributed under the terms of the Creative Commons Attribution License (http://creativecommons.org/licenses/by/2.0), which permits unrestricted use, distribution, and reproduction in any medium, provided the original work is properly credited. The Creative Commons Public Domain Dedication waiver (http://creativecommons.org/publicdomain/zero/1.0/) applies to the data made available in this article, unless otherwise stated. 


\section{Background}

The SA pathway is the common route leading to the biosynthesis of aromatic compounds in bacteria and in several eukaryotic organisms such as ascomycetes fungi, Apicomplexa, and plants [1,2]. In Escherichia coli, the first step in this pathway is the condensation of the CCM intermediates PEP and E4P, into DAHP by the DAHP synthase isoenzymes AroF, AroG, and AroH, which are encoded by the aroF, aroG, and aroH genes, respectively (Figure 1). The DHQ synthase, encoded by aroB, converts DAHP into DHQ. Subsequently, DHQ dehydratase, encoded by aroD, converts DHQ into DHS, and this compound is then transformed to SA by shikimate dehydrogenase, which is encoded by aroE. Shikimate kinases I and II, encoded by aroL and aroK, respectively, convert SA into S3P. Finally, S3P is converted to EPSP by 3-phosphoshikimate-1-carboxyvinyltransferase, which is encoded by aro $A$. The last step in the SA pathway is the synthesis of CHA by the CHA synthase enzyme, which is encoded by aroC. CHA is the common building block for the formation of aromatic amino acids and compounds such as quinone, menaquinone and enterobactin [3-5].

SA is a commercially important compound because it is considered to be an enantiomerically pure building block that is used as the precursor for the synthesis of numerous chemicals. Currently, SA has gained great importance as the starting compound for the chemical synthesis of OSP, the selective and potent inhibitor of the neuraminidase enzyme located on the surface of the influenza virus, known commercially as Tamiflu ${ }^{\oplus}$ and produced by Roche Pharmaceuticals [3-5]. OSP prevents the release of newly formed virus particles from influenza virus types $A$ and $B$, avian influenza virus $\mathrm{H} 5 \mathrm{~N} 1$ and, recently, human influenza virus H1N1. Since 1999, Roche Pharmaceuticals increased the production of OSP to ensure a significant reservoir in several countries in anticipation of a possible pandemic influenza outbreak; however, it has been estimated that in this scenario, the production of the antiviral would be insufficient to cover the requirements of the world population [6,7], particularly in developing countries such as Mexico. The latest human influenza outbreak, which appeared in Mexico in 2009 , showed that production of OSP is clearly insufficient to satisfy the demand for this antiviral in an emergency situation. Additionally, the main supply of SA for OSP production is currently derived from the seeds of Chinese star anise (Illicium verum). The supply of this source is susceptible to vagaries of the weather. The star anise plant takes around six-years from planting to bear fruit but remains productive for a long time; additionally, extraction and purification from its seeds results in low yields. Thus, alternative biotechnological strategies with engineered bacterial strains to produce SA have gained relevance $[4,5]$.

Metabolically engineered E. coli strains for SA production include several genetic modifications in CCM such as the introduction of an additional plasmid-copy DAHPS AroF ${ }^{\mathrm{fbr}}$, encoded by $\operatorname{aroF}^{\mathrm{fbr}}$ or DAHPS AroG ${ }^{\mathrm{fbr}}$ $\left(\operatorname{aro} G^{\mathrm{fbr}}\right)$, the $t k t A$ gene encoding transketolase I, and genes encoding enzymes from the SA pathway, including the single or double inactivation of genes aroK and $a r o L$,

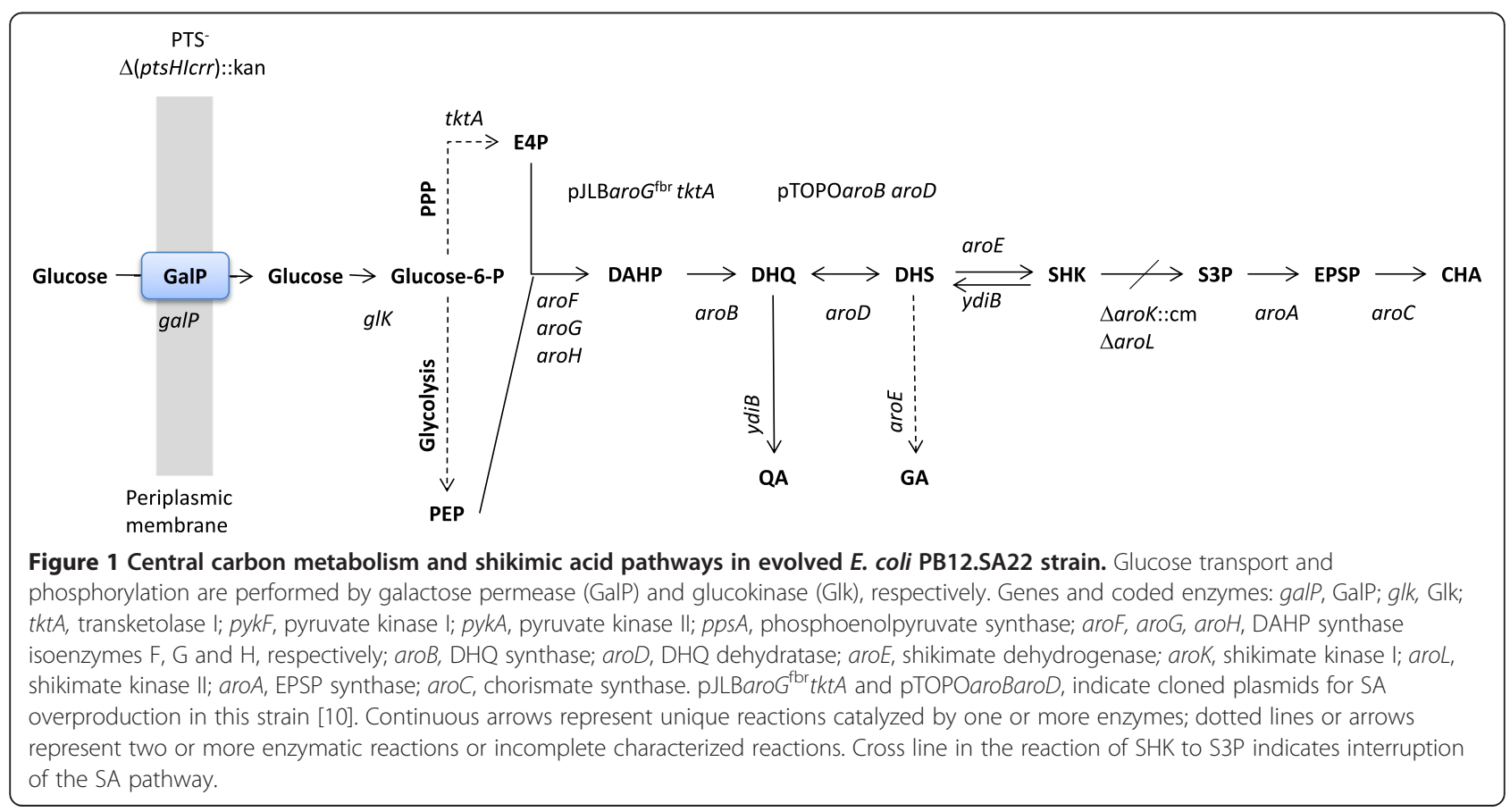


and the introduction of an additional plasmid-copy of genes encoding limiting enzymes of the pathway such as $a r o B$ and aroE, resulting in an increased carbon flux from the CCM intermediates PEP and E4P to the SA pathway and accumulation of SA. The above-described genetic modifications in specific $E$. coli genetic backgrounds with additional modifications and grown under diverse culture conditions have resulted in the successful overproduction of SA with yields ranging from 0.08 to $0.42 \mathrm{~mol} \mathrm{SA} / \mathrm{mol}$ glucose [8-13] (Table 1).

Previous characterization of SA production in strain PB12.SA22 in 0.5-L batch-fermentor cultures using complex fermentation broth including $25 \mathrm{~g} / \mathrm{L}$ of glucose and $15 \mathrm{~g} / \mathrm{L}$ of YE showed a characteristic two-phase growth behavior with an initially EXP growth with high $\mu$ while consuming $\sim$ one-third of the initially added glucose and low level production of SA and other pathway intermediates. During the second growth phase, the $\mu$ decreased, and the culture entered the STA phase despite the presence of abundant residual glucose in the supernatant broth, whereas SHK pathway intermediate production increased, continuously reaching its maximum until the end of the fermentation (50 h). Interestingly, residual glucose was depleted from supernatant culture during the STA phase associated with SA production [10]. This growth, glucose consumption and SA production behavior suggest that during the EXP growth phase, strain PB12.SA uses YE components to support growth and, as consequence of the possible depletion of an essential nutrient component, cell ceases growth upon entering the STA phase, where residual glucose was channeled by this strain to produce SA and other pathway intermediates. These data suggest the presence of important genetic regulation and physiological differences during the EXP and STA phases.
GTA has been proven to be a powerful tool to study regulation of cellular metabolism in response to specific environmental conditions. To our knowledge, in relation to SA production in E. coli, GTA has been used to elucidate byproduct formation in the SA production strain W3110.shik1 under carbon and phosphate-limited (carbon-rich) chemostat conditions, suggesting that byproduct formation under carbon limitation is explained by the upregulation of a set of genes coupled to the SA pathway [14]. In this study, we report the GTA in strain PB12.SA22 during SA production in batch-fermentor cultures using complex fermentation broth including $25 \mathrm{~g} / \mathrm{L}$ of glucose and 15 of g/L YE. GTA was determined in this strain in the mid EXP growth phase $(5 \mathrm{~h})$, at the beginning of the STA phase (STA1) $(9 \mathrm{~h})$ and in the late STA phase (STA2) (44 h), and the comparison of differentially upregulated genes was established during the EXP/STA1, EXP/STA2 and STA1/STA2 phases to correlate changes in the global expression profile and growth, glucose consumption and SA production profiles in this strain.

\section{Results}

\section{Growth and SA pathway intermediate production}

Based on growth and glucose consumption profiles, strain PB12.SA22 showed its characteristic two-phase growth behavior [10], with an initial EXP growth phase during the first $8 \mathrm{~h}$ of cultivation reaching an $\mathrm{OD}_{600 \mathrm{~nm}}=$ 13.37 with a $\mu=0.47 \pm 0.002 \mathrm{~h}^{-1}$ and a $q_{S}=3.34 \pm$ $0.29 \mathrm{mmol}$ glucose $\mathrm{g} \mathrm{DW} \mathrm{DW}^{-1} \mathrm{~h}^{-1}$. After $8 \mathrm{~h}$ of cultivation, the culture reduced its growth rate even in the presence of $\sim 70 \%$ of initially added glucose in the fermentation broth, and after $10 \mathrm{~h}$ of cultivation, the strain entered into a pseudo-STA phase in which a low growth phase was observed until $26 \mathrm{~h}$ of cultivation, where the highest

Table 1 E. coli SA engineered overproducing strains, growth conditions and SA yield

\begin{tabular}{|c|c|c|c|c|c|}
\hline Strain/derivative & Relevant characteristics & Culture conditions & $\begin{array}{c}S A \\
{[g / L]}\end{array}$ & $\begin{array}{l}\text { Yield (mol } \\
\mathrm{SA} / \mathrm{mol} \text { glucose) }\end{array}$ & Reference \\
\hline SP1.1/pKD12.138 & $\begin{array}{l}\text { serA::aroB } \triangle \text { arol } \triangle a r o K \text { pSU18arof fbrptac } a r o E \\
\text { serA tktA }\end{array}$ & $\begin{array}{l}\text { 1- } \mathrm{L} \text { fed-batch cultures, mineral broth } \\
\text { with } 25 \mathrm{~g} / \mathrm{L} \text { of glucose and } 15 \mathrm{~g} / \mathrm{L} \text { of } \mathrm{YE}\end{array}$ & 52 & 0.18 & [8] \\
\hline SP1.1pts/pSC6.090B & $\begin{array}{l}\mathrm{PTS}^{-} \text {serA::aroB } \triangle \text { arol } \Delta \text { aroK } \mathrm{PTS}^{-} \mathrm{P}^{\mathrm{tac}} \text { glf glk } \\
\text { arof } F^{\text {fbr }} \text { tktA } \mathrm{P}^{\mathrm{tac}} \text { aroE serA, glf } \mathrm{flk}^{2}\end{array}$ & $\begin{array}{l}\text { 10-L fed-batch reactors, mineral broth } \\
\text { with } 25 \mathrm{~g} / \mathrm{L} \text { of glucose and } 15 \mathrm{~g} / \mathrm{L} \text { of } \mathrm{YE}\end{array}$ & 71 & 0.27 & {$[8]$} \\
\hline W3110.shik1 & $\begin{array}{l}\Delta \text { arol arof } \mathrm{fbr}^{\mathrm{fb}} \operatorname{arof}^{\mathrm{fbr}} \text { tnaA, and plasmid } \\
\text { overexpressed aroK }\end{array}$ & $\begin{array}{l}\text { Chemostat cultures using mineral broth } \\
\text { under glucose limiting conditions }\end{array}$ & NR & $\sim 0.08$ & [9] \\
\hline $\begin{array}{l}\text { PB12.SA22 (JM101 } \\
\text { derivative) }\end{array}$ & $\begin{array}{l}\mathrm{PTS}^{-} \Delta \text { aroL } \Delta \text { aroK pJLBaro } G^{\mathrm{fbr}} \text { tktA pTOPO } \\
\text { aroB aroE }\end{array}$ & $\begin{array}{l}0.5-\mathrm{L} \text { batch reactors, mineral broth with } \\
25 \mathrm{~g} / \mathrm{L} \text { of glucose and } 15 \mathrm{~g} / \mathrm{L} \text { of } Y E\end{array}$ & 7 & 0.29 & {$[10]$} \\
\hline $\begin{array}{l}\text { DHPYAAS-T7(DH5a- } \\
\text { derivative) }\end{array}$ & $\begin{array}{l}\Delta p t s H / c r r \Delta \text { arol } \Delta \text { arok } \Delta y d i B \text { knock-in of } \\
\text { T7-RNA-pol gene, pAOC-TGEFB aroE aroB, } \\
\text { site-specific mutagenesis glk tktA arof for }\end{array}$ & $\begin{array}{l}\text { Fed-batch fermentation, modified M9 } \\
\text { medium, with } 25 \mathrm{~g} / \mathrm{L} \text { of glycerol and } \\
25 \mathrm{~g} / \mathrm{L} \text { of } \mathrm{YE}\end{array}$ & 1.85 & NR & [11] \\
\hline $\begin{array}{l}\text { AR36 (JM101 } \\
\text { derivative) }\end{array}$ & 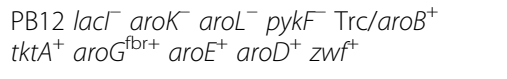 & $\begin{array}{l}\text { Batch fermentation, mineral broth with } \\
100 \mathrm{~g} / \mathrm{L} \text { of glucose and } 30 \mathrm{~g} / \mathrm{L} \text { of } \mathrm{YE}\end{array}$ & 43 & 0.42 & {$[12]$} \\
\hline E. coli SA116 & $\begin{array}{l}\text { Chromosomally evolved and cofactor } \\
\text { metabolic engineered strain }\end{array}$ & $\begin{array}{l}\text { Mineral broth with } 10 \mathrm{~g} / \mathrm{L} \text { of glucose, } \\
1 \mathrm{~g} / \mathrm{L} \text { of peptone, } 1.24 \mathrm{~g} / \mathrm{L} \text { of proline }\end{array}$ & 3.12 & 0.33 & [13] \\
\hline
\end{tabular}

${ }^{1}$ Glucose facilitator $(g / f)$ and ${ }^{2}$ Glucokinase ( $\left.g / k\right)$ from Zymomonas mobilis; NR, Non-reported. 
$\mathrm{OD}_{600 \mathrm{~nm}}=15.77$ was observed. During this period, the strain completely consumed the residual glucose present in the supernatant broth (showing a $q_{S}=2.68 \pm 0.5 \mathrm{mmol}$ glucose $g \mathrm{DW}^{-1} \mathrm{~h}^{-1}$ ). From this point to the end of the fermentation, the biomass showed a slight reduction to $\mathrm{OD}_{600 \mathrm{~nm}} \sim 15$ (Figure 2A). Interestingly, analysis of the consumption profile of available supernatant aromatic amino acids by HPLC showed that strain PB12.SA22 totally consumed the tryptophan present in the YE during EXP growth, reducing its growth when this aromatic amino acid was completely depleted from the culture supernatant (Figure 2B). SA production was detected in
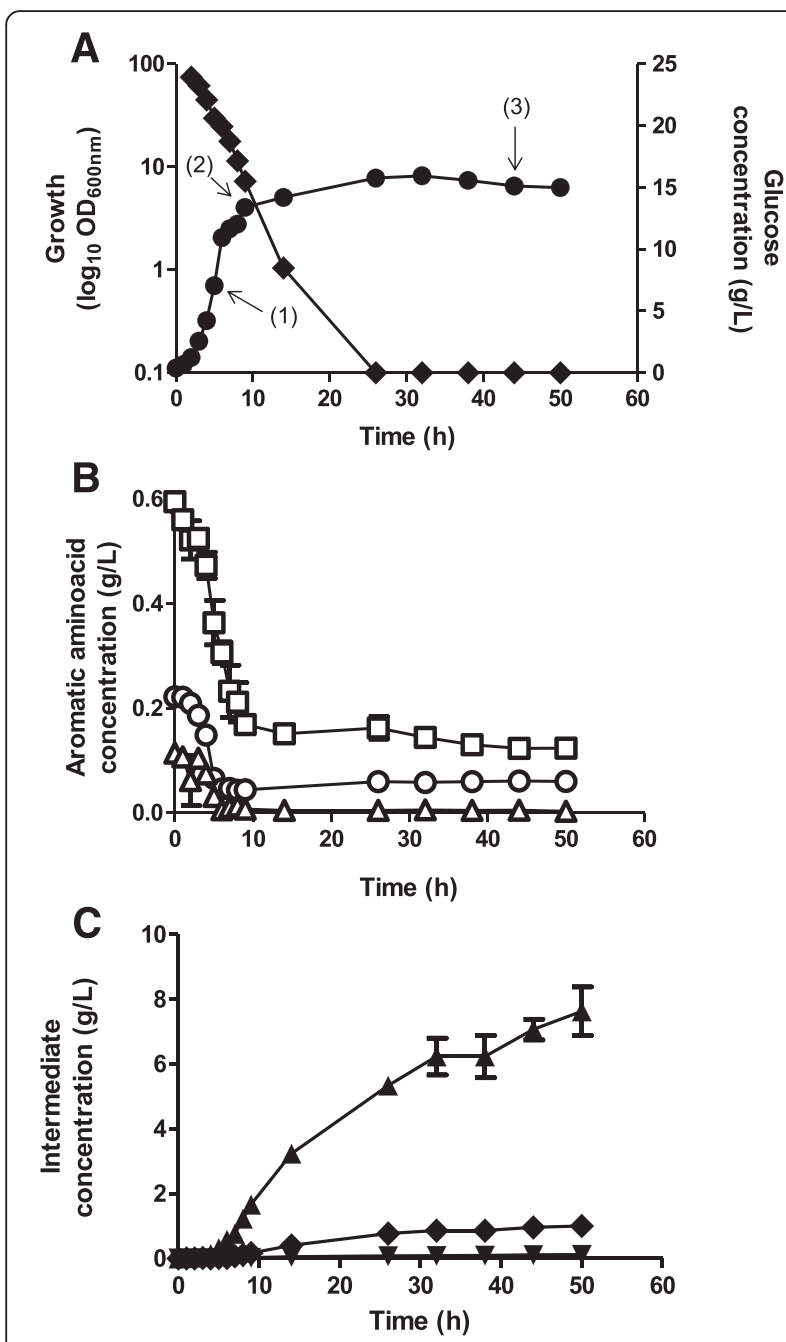

Figure 2 Growth, aromatic intermediates production, and substrate consumption during batch fermentation cultures of E. coli PB12.SA22 strain grown in complex broth. (A) Biomass production $(\bullet)$ Glucose consumption $(\bullet)$. (B) Residual Phenylalanine $(\square)$, Tyrosine (o), Tryptophan ( $\Delta$ ). (C) SA ( $(\boldsymbol{\Delta})$, DHS $(\bullet), G A(\boldsymbol{\nabla})$ production. In panel $\mathrm{A}$, numbers in parenthesis indicate the sampling time of biomass for total RNA extraction used for microarray analysis (1), (2) and (3) indicates samples collected at 5, 9, and $44 \mathrm{~h}$ of cultivation, respectively. supernatant cultures in the EXP phase, but the highest SA accumulation was observed during the last $24 \mathrm{~h}$, accumulating $7.63 \mathrm{~g} / \mathrm{L} \mathrm{SA}$ at the end of fermentation $(50 \mathrm{~h})$ (Figure $2 \mathrm{C})$. The determined SA pathway byproducts, DAHP, DHS, and GA, appeared to be associated with growth because their production remained relatively constant after strain PB12.SA22 entered the STA phase. SA production resulted in a yield of $0.31 \mathrm{~mol} \mathrm{SA} /$ mol glucose, and the total aromatic yield (the combined yield of SA, DAHP, DHS, and GA) was $0.36 \mathrm{~mol}$ aromatic intermediates/mol glucose.

\section{Global transcriptomic analysis during the EXP and STA phases}

GTA analysis was determined by triplicate in the middle of the EXP phase $(5 \mathrm{~h})$, at the end of the EXP growth phase and upon entering pseudo-STA phase $(9 \mathrm{~h})$ (STA1) and at the end of the fermentation, or the late STA phase (44 h) (STA2). Average expression data were compared among EXP/STA1, EXP/STA2, and STA1/ STA2, using the expression data of 4070 genes from the array of $E$. coli MG1655 included in the Affymetrix GeneChip ${ }^{\circ}$ E. coli Genome 2.0 by the RP method. For all expression data, the RP method calculated a FDR. Those genes with an FDR value $=0$ have the highest probability of biological relevance $[15,16]$. To identify differentially expressed (upregulated and downregulated) genes among compared growth conditions, an FDR value cutoff $\leq 0.05$ was used. This analysis resulted in the identification of the significant upregulation of 43 genes and the downregulation of 80 genes in EXP/STA1, the upregulation of 37 genes and the downregulation of 38 genes in EXP/STA2, and the upregulation of 50 genes and the downregulation of 47 genes in ST1/STA2 (Table 2). Among them, 22 common genes were found to be upregulated during the entire fermentation process (EXP, STA1 and STA2). Biological functions were assigned to upregulated genes according to the EcoCyc database for E. coli strain MG1655 and broadly grouped on the basis of GO terms [17].

Initial GTA data mining for upregulated genes in EXP/STA1 (Table 3), EXP/STA2 (Table 4), and STA1/ STA2 (Table 5) comparisons resulted from the RP analysis from average transcription data for genes encoding enzymes involved in glycolysis, PPP, TCA, and the glyoxylate shunt, acetate metabolism and gluconeogenic capabilities in the EXP, STA1 and STA2 phases, showed that genes encoding proteins of the CCM and SA pathways were not significantly upregulated among performed comparisons (Additional file 1). However, significantly upregulated genes detected during the EXP and STA phases suggest important differences in sugar, amino acid, nucleotide/nucleoside and ion transport; metabolic process, particularly amino acid catabolism and biosynthesis; nucleotide/nucleoside salvage; acid stress response and 
Table 2 Differentially expressed genes during EXP/STA1, EXP/STA2 and STA1/STA2 comparisons during SA production ${ }^{a}$

\begin{tabular}{|c|c|c|c|c|c|c|}
\hline \multirow[t]{2}{*}{ GO terms ${ }^{b}$} & \multicolumn{2}{|c|}{ EXP/STA1 } & \multicolumn{2}{|c|}{ EXP/STA2 } & \multicolumn{2}{|c|}{ STA1/STA2 } \\
\hline & UP & DR & UP & DR & UP & DR \\
\hline Transport & 15 & 9 & 9 & 5 & 8 & 10 \\
\hline Amino acid metabolism & 9 & 15 & 8 & ND & 16 & 4 \\
\hline Electron carrier activity & 2 & ND & 1 & ND & 3 & ND \\
\hline Out of GOs & 2 & 21 & 4 & 8 & 4 & 14 \\
\hline ATP catabolic/biosynthetic process & 2 & 1 & ND & ND & ND & ND \\
\hline Nucleotide/nucleoside metabolism & 6 & 2 & 1 & ND & ND & 2 \\
\hline Sulfur metabolism & 2 & ND & 4 & ND & 2 & ND \\
\hline Stress response & 1 & 12 & 2 & 6 & 5 & 3 \\
\hline Catalytic activity & 1 & ND & 1 & ND & ND & ND \\
\hline Regulatory & 2 & 7 & 4 & 7 & 4 & 4 \\
\hline Cell envelope & ND & 5 & 2 & 7 & 1 & 4 \\
\hline Structural molecule activity & 1 & ND & 1 & ND & ND & ND \\
\hline Lipid metabolism & ND & 1 & ND & ND & 3 & ND \\
\hline Other metabolic process & ND & 7 & ND & 5 & 4 & 6 \\
\hline Total gene number & 43 & 80 & 37 & 38 & 50 & 47 \\
\hline
\end{tabular}

${ }^{\mathrm{a}}$ Based on resultant FDR value from the RP analysis equal or less to 0.05 [15]; ${ }^{\mathrm{b}}$ Biological functions were assigned according to the EcoCyc database for $E$. coli strain MG1655 and broadly grouped on the basis of GO terms [17]. ND, Non-detected.

modification of the IM. A detailed list of those differentially expressed genes in the EXP/STA1, EXP/STA2 and STA1/STA2 comparisons, expression data and FDR values information are presented in Additional file 1. The role and the relationship with growth, substrate consumption and SA production of relevant upregulated genes during EXP/STA1, EXP/STA2 and STA1/ STA2 will be discussed below.

\section{Discussion}

Upregulation of genes involved in sugar transport

Genes encoding sugar transporters that were found to be upregulated in the EXP/STA1 comparison included the sugar porin $\operatorname{LamB}(\operatorname{lam} B)$, the periplasmic binding protein, the membrane subunit and the ATP binding subunit components of the $\mathrm{ABC}$ maltose transport system (malE and malFK, respectively) [17] and the GlpT glycerol 3-P MFS transporter ( $g l p T)$, whereas in the EXP/STA2 comparison, the upregulation of the nonspecific OMP ompC (OmpC), a general porin and the periplasmic binding protein of the maltose $A B C$ transporter (malE) was observed. A previous transcriptomic analysis of our group determined by RT-qPCR in cultures of the parental strain PB12 in M9 minimal broth showed the upregulation of the galP gene, suggesting that GalP protein is the main transporter used for glucose import in this PTS $^{-}$strain [18], as is the case in a derived PB12 strain for L-Phe production grown in M9 broth supplemented with $5 \mathrm{~g} / \mathrm{L}$ of YE [19]. However, our GTA showed that in the SA-producing strain PB12. SA22, the galP gene was not significantly upregulated during EXP growth and the STA phase. This result was also observed in GTA for the parental strain PB12 in the same culture conditions (data not shown), suggesting that in both strains grown in complex fermentation broth for SA production, the OMP OmpC, LamB, and the maltose $\mathrm{ABC}$ transporter, have an important role in the transport of glucose because previous works reported the participation of these proteins in the uptake of glucose in E. coli [20-23]. All these genes were found to be upregulated in the EXP and STA1 phases, associated with the consumption of $>30 \%$ of the initially added glucose to the fermentation broth; however, only in the STA1/ STA2 comparison was detected the upregulation of ompC. Differential expression of these transporters is in agreement with the absence of glucose in the supernatant culture observed at the middle STA phase $(26 \mathrm{~h})$. Interestingly, the gene encoding the glycerol-3-P (G3P) MFS transporter (GlpT) $(g l p T)$ was also detected upregulated during the EXP/STA1 comparison but not during STA1/STA2. G3P plays a major role in glycolysis and phospholipid biosynthesis in E. coli. G3P is transported by GlpT and is reduced by aerobic or anaerobic G3P dehydrogenase into dihydroxyacetone phosphate, which is converted into fructose-1,6-diphosphate or glyceraldehyde-3-phosphate and then enters the glycolysis pathway. In phospholipid biosynthesis, G3P forms the backbone of all phospholipid molecules and the polar groups of phosphatidylglycerol 
Table 3 Average expression data of upregulated genes during EXP/STA1 comparison based on resultant FDR value from the RP analysis equal or less to 0.05 in compared growth phases during SA production cultures

\begin{tabular}{|c|c|c|c|c|}
\hline Gene & Locus & Protein name ${ }^{a}$ & Cellular function ${ }^{\mathrm{b}}$ & $\begin{array}{l}\text { Average } \\
\text { expression }\end{array}$ \\
\hline $\operatorname{asn} A$ & b3744 & Asparagine synthetase A & Amino acid metabolism & 28.5470 \\
\hline $\operatorname{aspA}$ & b4139 & Aspartate ammonia-lyase & Amino acid metabolism & 5.7446 \\
\hline$g c v H$ & b2904 & Glycine cleavage system $\mathrm{H}$ protein & Amino acid metabolism & 7.2457 \\
\hline$g \subset v P$ & b2903 & Glycine decarboxylase & Amino acid metabolism & 12.2509 \\
\hline$g c v T$ & b2905 & Aminomethyltransferase & Amino acid metabolism & 12.0966 \\
\hline putA & b1014 & $\begin{array}{l}\text { Fused PutA DNA-binding transcriptional repressor/proline dehydrogenase/ } \\
\text { 1-pyrroline-5-carboxylate dehydrogenase }\end{array}$ & Amino acid metabolism & 11.8149 \\
\hline$s d a B$ & b2797 & L-serine deaminase $\|$ & Amino acid metabolism & 8.2308 \\
\hline thaA & b3708 & L-cysteine desulfhydrase/tryptophanase & Amino acid metabolism & 60.3464 \\
\hline tnal & b3707 & tha operon leader peptide & Amino acid metabolism & 91.7140 \\
\hline $\operatorname{atp} G$ & b3733 & ATP synthase $F_{1}$ complex - gamma subunit & ATP biosynthetic/catabolic process & 5.5487 \\
\hline fecE & b4287 & Ferric dicitrate $A B C$ transporter - ATP binding subunit & ATP biosynthetic/catabolic process & 7.0184 \\
\hline ompT & b0565 & OM protease VII (OM protein 3b) & Catalytic activity & 6.0698 \\
\hline gros & B4142 & $\begin{array}{l}\text { Polypeptide: GroES, chaperone binds to Hsp60 in pres. Mg-ATP, suppressing its } \\
\text { ATPase activity }\end{array}$ & Cell processes & 5.9806 \\
\hline CyoB & b0431 & Cytochrome bo terminal oxidase subunit I & Electron carrier activity & 6.3920 \\
\hline$c y o D$ & b0429 & Cytochrome bo terminal oxidase subunit IV & Electron carrier activity & 6.6316 \\
\hline gpt & b0238 & Xanthine-guanine phosphoribosyltransferase & Nucleotide/nucleoside metabolism & 6.4026 \\
\hline guac & b0104 & GMP reductase & Nucleotide/nucleoside metabolism & 6.7694 \\
\hline pyrB & b4245 & Aspartate carbamoyltransferase, catalytic subunit & Nucleotide/nucleoside metabolism & 10.8487 \\
\hline rihA & b0651 & Ribonucleoside hydrolase 1 (pyrimidine-specific) & Nucleotide/nucleoside metabolism & 5.9568 \\
\hline upp & b2498 & Uracil phosphoribosyltransferase & Nucleotide/nucleoside metabolism & 5.4210 \\
\hline ylif & b0834 & Predicted diguanylate cyclase & Nucleotide/nucleoside metabolism & 5.6595 \\
\hline$n / p A$ & b3661 & Lipoprotein-28 & Out of GOs & 7.2359 \\
\hline yiel & b3716 & Predicted IM protein & Out of GOs & 6.6363 \\
\hline$g \subset v B$ & b4443 & GcvB small regulatory RNA & Regulatory & 7.4984 \\
\hline yeeN & b1983 & Conserved protein & Regulatory & 5.3142 \\
\hline rihA & b4142 & GroES, chaperone binds to Hsp60 in pres. Mg-ATP, suppressing its ATPase activity & Stress response & 5.9806 \\
\hline CYOE & b0428 & Heme O synthase & Structural molecule activity & 5.9183 \\
\hline cysC & B2750 & Adenylylsulfate kinase & Sulfur metabolism & 7.0141 \\
\hline cysH & b2762 & 3'-Phospho-adenylylsulfate reductase & Sulfur metabolism & 11.2772 \\
\hline cirA & b2155 & OM receptor involved in uptake of ferric dihyroxybenzoylserine & Transport & 9.4700 \\
\hline fecA & b4291 & Ferric citrate OMP FecA & Transport & 19.9369 \\
\hline$f e c B$ & b4290 & Ferric dicitrate $A B C$ transporter - periplasmic binding protein & Transport & 14.5864 \\
\hline fruB & b2169 & Fructose PTS permease - FruB subunit & Transport & 5.8528 \\
\hline glpT & b2240 & GlpT glycerol-3-P MFS transporter & Transport & 8.6190 \\
\hline $\operatorname{lam} B$ & b4036 & Phage lambda receptor protein; maltose high-affinity receptor & Transport & 18.0411 \\
\hline livk & b3458 & Leucine $A B C$ transporter - periplasmic binding protein & Transport & 6.0726 \\
\hline male & b4034 & Maltose $A B C$ transporter - periplasmic binding protein & Transport & 174.0512 \\
\hline malF & b4033 & Maltose $A B C$ transporter - membrane subunit & Transport & 19.1719 \\
\hline malk & b4035 & Maltose ABC transporter - ATP binding subunit & Transport & 14.8026 \\
\hline$n m p C$ & b0553 & OMP protein; locus of qsr prophage & Transport & 11.7561 \\
\hline proX & b2679 & Glycine betaine/proline $A B C$ transporter - periplasmic binding protein & Transport & 7.3363 \\
\hline
\end{tabular}


Table 3 Average expression data of upregulated genes during EXP/STA1 comparison based on resultant FDR value from the RP analysis equal or less to $\mathbf{0 . 0 5}$ in compared growth phases during SA production cultures (Continued)

\begin{tabular}{|c|c|c|c|c|}
\hline$s b p$ & b3917 & Sulfate/thiosulfate $A B C$ transporter - periplasmic binding protein Sbp & Transport & 11.2712 \\
\hline $\operatorname{tn} a B$ & b3709 & TnaB tryptophan ArAAP transporter & Transport & 9.9672 \\
\hline $\operatorname{ts} x$ & b0411 & Nucleoside channel; receptor of phage T6 and colicin K & Transport & 6.2757 \\
\hline
\end{tabular}

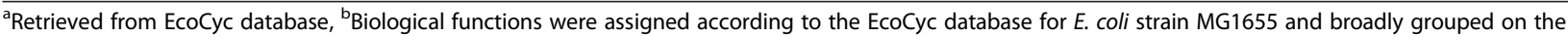
basis of GO terms [17].

and cardiolipin [24]. Upregulation of this gene in strain PB12.SA22 is intriguing because G3P was not present during the SA production cultures. GlpT could be involved in phospholipid biosynthesis during the EXP/STA1 comparison because it was previously reported, and indirect evidence suggests that GlpT expression may be regulated by a byproduct from the glycerolipid biosynthetic pathway [24].

\section{Upregulation of genes involved in the amino acid transport and metabolism}

During the EXP/STA1 comparison, livK, encoding a subunit of the $A B C$ transporter for leucine, and tnaB (part of the tnaCAB operon) encoding the TnaB tryptophan ArAAP transporter, which is proposed to be involved in tryptophan scavenging [25], were upregulated. The EXP/STA2 comparison revealed the upregulation of the genes for the putative membrane protein and the ATP binding components of the BppBCDF dipeptide $\mathrm{ABC}$ transporter $(d p p B$ and $d p p F)$, which is associated with the transport of proline-glycine as source of proline, histidine-glutamic acid, and leucine-tryptophan [26,27]; the putative membrane protein of the murein tripeptide $\mathrm{ABC}$ transport system (oppB), which can transport oligopeptides of up to five residues in length as well as recycle cell-wall peptides, but it has been reported to lack affinity for free amino acids [28-31]; and the complete glycine betaine/proline $\mathrm{ABC}$ transporter encoded by the proVWWX operon [17]. Expression of this operon was reported to substantially increase at high osmolarity to scavenge glycine, betaine, proline, taurine, ectoine, carnitine as the precursor for betaine, and choline to achieve high intracellular concentrations of these osmoprotectants [32-34]. During the STA1/STA2 comparison, the periplasmic binding protein of the arginine $\mathrm{ABC}$ transporter (art)); the 4-aminobutyrate antiporter glutamic acid GadC $(\operatorname{gadC})$, a member of the APC superfamily of amino acid transporters [35]; and the integral membrane subunit and the ATP-binding component of the lysine/arginine/ornithine $\mathrm{ABC}$ transporter and the histidine $\mathrm{ABC}$ transporter (hisM and hisP, respectively) were found to be upregulated [17].

Differential upregulation of those genes encoding peptide and amino acid transporters during the entire fermentation process suggests that during batch culture for
SA production, strain PB12.SA22 imports the substrates that are available in the fermentation broth into the cell because they are supplied by YE, which contains $6 \%$ amino nitrogen, supplying peptides and 18 of the 20 proteinogenic amino acids (with the exception of asparagine and glutamine) [36]; however, differential upregulation of amino acid transporters observed during the EXP, STA1 and STA2 phases suggests a possible differential amino acid requirement by the cell during the fermentation process, particularly for leucine and tryptophan during the EXP/STA1 comparison and leucine, arginine, glutamic acid, lysine and histidine during the STA1/STA2 comparison. Amino acid availability in the fermentation broth provided by YE almost certainly alleviates the cellular requirements because YE contains all these amino acids [36]. Finally, in the EXP/STA1 and EXP/STA2 comparisons, ompT, encoding protease VII was upregulated; this protein is capable of cleaving several peptides at the center of paired basic residues but not at single basic residues, suggesting a distinct mechanism for trypsin-like proteases [17]. Although OmpT is not involved in transport, it is possibly related to peptide assimilation in strain PB12.SA22 during SA production.

Together with the upregulation of genes encoding peptide and amino acid transporters, several genes encoding enzymes involved in amino acid catabolic or biosynthetic pathways were differentially upregulated during the EXP growth and STA phases. Among biosynthetic genes encoding the enzymes involved in the complete cysteine biosynthesis from sulfate, $\mathrm{CysD}$, CysC, $\mathrm{CysH}$ (cysD, cys C and cysH, respectively) [17] were found upregulated during the EXP/STA2 and STA1/ STA2 comparisons, while CysJ (cisJ), encoding sulfite reductase $(\mathrm{NADPH})$, which catalyzes the 6-electron reduction of sulfite to sulfide, one of several activities necessary for the biosynthesis of cysteine from sulfate [17], was found to be upregulated only in the EXP/STA1 comparison. During the EXP/STA2 comparison, we detected the upregulation of those genes encoding hydroxymethyltransferase $(g l y A)$ involved in the conversion of serine to glycine; the enzyme cysteine synthase A (cysK) catalyzing the conversion of O-acetyl-L-serine to L-cysteine [37-39] (although, in the absence of a sulfur source, this enzyme catalyzes the slow conversion of Oacetyl-L-serine into pyruvate + acetate + ammonia, or the 
Table 4 Average expression data of upregulated genes during EXP/STA2 comparison based on resultant FDR value from the RP analysis equal or less to 0.05 in compared growth phases during SA production cultures

\begin{tabular}{|c|c|c|c|c|}
\hline Gene & Locus & Protein name ${ }^{a}$ & Cellular function $\mathrm{GO}^{\mathrm{b}}$ & $\begin{array}{l}\text { Average } \\
\text { expression }\end{array}$ \\
\hline$y k f E$ & b0220 & (ivy) Protein: inhibitor of vertebrate C-type lysozyme & Amino acid metabolism & 29.2978 \\
\hline cysk & b2414 & Enzyme: cysteine synthase A & Amino acid metabolism & 83.0796 \\
\hline gCvH & b2904 & Polypeptide: glycine cleavage system $\mathrm{H}$ protein & Amino acid metabolism & 30.4955 \\
\hline$g \subset v P$ & b2903 & Enzyme: glycine decarboxylase & Amino acid metabolism & 33.3045 \\
\hline$g c v T$ & b2905 & Enzyme: aminomethyltransferase & Amino acid metabolism & 38.3509 \\
\hline gdhA & b1761 & Enzyme: glutamate dehydrogenase & Amino acid metabolism & 20.9785 \\
\hline glyA & b2551 & Enzyme: serine hydroxymethyltransferase & Amino acid metabolism & 23.7380 \\
\hline tnaA & _b3708 & L-cysteine desulfhydrase/tryptophanase & Amino acid metabolism & 139.6125 \\
\hline thal & b3707 & tha operon leader peptide & Amino acid metabolism & 62.9786 \\
\hline ompT & b0565 & Enzyme: OM protease VII (OM protein 3b) & Catalytic activity & 35.7201 \\
\hline $\operatorname{fim} C$ & b4316 & Polypeptide: periplasmic chaperone, required for type 1 fimbriae & Cell envelope & 63.3469 \\
\hline fimD & b4317 & Polypeptide: OM protein; export and assembly of type 1 fimbriae & Cell envelope & 25.6637 \\
\hline$n / p A$ & b3661 & Polypeptide: lipoprotein-28 & Cell envelope & 48.3194 \\
\hline ydiQ & b1697 & Polypeptide: putative subunit of YdiQ-YdiR flavoprotein & Electron carrier activity & 29.9950 \\
\hline $\operatorname{nrdA}$ & b2234 & Protein: ribonucleoside diphosphate reductase 1, a subunit dimer & $\begin{array}{l}\text { Nucleotide/nucleoside } \\
\text { metabolism }\end{array}$ & 37.6063 \\
\hline yciW & b1287 & Polypeptide: predicted oxidoreductasePolypeptide: predicted oxidoreductase & Out of GOs & 116.1438 \\
\hline yiel & b3716 & (cbrB) Polypeptide: predicted IM protein & Out of GOs & 31.9090 \\
\hline yeeN & b1983 & Polypeptide: conserved protein & Regulatory & 22.0828 \\
\hline yhiE & b3512 & (gadE) Polypeptide: GadE DNA-binding transcriptional activator & Regulatory & 46.2077 \\
\hline yhiw & b3515 & (gadW) Polypeptide: GadW DNA-binding transcriptional dual regulator & Regulatory & 37.7545 \\
\hline hdeA & b3510 & Protein: HdeA dimer, inactive form of acid-resistance protein & Stress response & 32.4174 \\
\hline hdeB & b3509 & Polypeptide: acid stress chaperone & Stress response & 56.2185 \\
\hline b0023 & b0023 & Polypeptide: 30 S ribosomal subunit protein $\mathbf{S} 20$ & Structural molecule activity & 45.8728 \\
\hline cysC & b2750 & Enzyme: adenylylsulfate kinase & Sulfur metabolism & 52.8463 \\
\hline cys D & cysD & Polypeptide: CysD & Sulfur metabolism & 236.2573 \\
\hline cysH & b2762 & Enzyme: 3'-phospho-adenylylsulfate reductase & Sulfur metabolism & 194.5029 \\
\hline cys」 & b2764 & Enzyme: sulfite reductase, flavoprotein subunit complex & Sulfur metabolism & 62.3545 \\
\hline$y d j N$ & b1729 & Polypeptide: predicted transporter & Transport & 43.4944 \\
\hline$d p p B$ & b3543 & Polypeptide: dipeptide $A B C$ transporter - putative membrane subunit & Transport & 23.0830 \\
\hline$d p p F$ & b3540 & Polypeptide: dipeptide $A B C$ transporter - putative $A B C$ binding subunit & Transport & 32.6107 \\
\hline fecA & b4291 & Polypeptide: ferric citrate OMP FecA & Transport & 23.6130 \\
\hline male & b4034 & Maltose $A B C$ transporter - periplasmic binding protein & Transport & 230.4651 \\
\hline ompC & b2215 & Transporter: OMP C & Transport & 61.2832 \\
\hline opp B & b1244 & $\begin{array}{l}\text { Polypeptide: murein tripeptide } A B C \text { transporter/peptide } A B C \text { transporter - putative } \\
\text { membrane subunit }\end{array}$ & Transport & 44.3550 \\
\hline prov & b2677 & Polypeptide: glycine betaine/proline ABC transporter - ATP binding subunit & Transport & 34.7488 \\
\hline prow & b2678 & $\begin{array}{l}\text { Polypeptide: glycine betaine/proline } A B C \text { transporter - membrane subunitPolypeptide: } \\
\text { glycine betaine/proline } A B C \text { transporter - membrane subunit }\end{array}$ & Transport & 35.6683 \\
\hline proX & b2679 & Polypeptide: glycine betaine/proline $A B C$ transporter - periplasmic binding protein & Transport & 48.2957 \\
\hline
\end{tabular}

${ }^{a}$ Retrieved from EcoCyc database, ${ }^{b}$ Biological functions were assigned according to the EcoCyc database for E. coli strain MG1655 and broadly grouped on the basis of $\mathrm{GO}$ terms [17]. 
conversion of O-acetyl-L-serine into simple serine [40]; and glutamate dehydrogenase $(g d h A)$ involved in the $\mathrm{NADPH}$-dependent amination of $\alpha$-ketoglutarate to yield L-glutamate. Catabolic genes upregulated during the EXP/STA1 and EXP/STA2 comparisons included tnaCA (part of the tnaCAB operon), which encodes the tryptophanase leader peptide and the tryptophanase involved in tryptophan degradation to indole + PYR + ammonia $+\mathrm{H}^{+}$. During the EXP/STA1 and EXP/STA2 comparisons, the entire glycine cleavage system (GCV) (gcvTHP operon), a multienzyme complex catalyzing the reversible oxidation of glycine, yielding carbon dioxide, ammonia, 5,10-methylenetetrahydrofolate and a reduced pyridine nucleotide $[17,41]$ was also upregulated. Tetrahydrofolate serves as a recipient for $C_{1}$ units generated during glycine cleavage to form the methylene group, which are of central physiological importance, as will be discussed below [41-43].

Another group of upregulated genes found during the EXP/STA1 comparison, were the genes involved in ammonia dependent conversion of aspartate to asparagine (amino acid not supplied by YE), by asparagine synthetase $(\operatorname{asn} A)$ and the catabolic genes involved in the conversion of aspartate to Fum + ammonia $+\mathrm{H}^{+}$by aspartate ammonia-lyase (asp $A$ ), which is the first step in the proline degradation pathway to glutamic acid by proline dehydrogenase (putA), and in serine degradation to PYR + ammonia $+\mathrm{H}^{+}$by L-serine deaminase II (sdaB) [17]. Notably, a group of upregulated genes during the STA1/STA2 comparison include genes encoding the entire arginine biosynthesis pathway and the ornithine biosynthesis pathway ( $\arg A, \arg C B H, \arg G, \arg D$ and $\operatorname{argI}$ ) and carbamoyl phosphate synthetase (carAB), which catalyzes the first committed step in the biosynthetic pathways for the production of arginine and pyrimidine nucleotides. The small subunit of this enzyme (carA) also hydrolyzes glutamine to glutamate and ammonia [44]. ilvG_1 and ilvG_2, part of the ilvLXG_1G_2MEDA operon [45], are pseudogenes encoding subunits of acetohydroxybutanoate synthase / acetolactate synthase, an essential enzyme that catalyzes the biosynthesis of $\alpha$ aceto- $\alpha$-hydroxybutyrate for the isoleucine pathway and of $\alpha$-acetolactate for the valine biosynthesis when E. coli $\mathrm{K}-12$ was grown on acetate or oleate as the sole carbon source [46]. Other genes upregulated in the STA1/STA2 comparison encode cobalamin-independent homocysteine transmethylase (metE), which catalyzes the final step of de novo methionine biosynthesis in the absence of exogenously supplied vitamin B12 (cobalamin); $\alpha$-keto glutarate reductase/D-3-phosphoglycerate dehydrogenase $(\operatorname{ser} A)$, which catalyzes the first committed step in the biosynthesis of L-serine from 3-P-glycerate; and glutaminase $(y b a S)$, which catalyzes the degradation of glutamine to yield glutamate [17].
The main cellular role of amino acids is as structural blocks for the synthesis of proteins. Their availability determines the growth capabilities of cells, thereby defining the extent of the EXP growth phase, particularly for auxotrophic strains. Because strain PB12.SA22 is auxotrophic for aromatic amino acids due to the deletion of the $\operatorname{aroK}$ and $a r o L$ genes, its growth depends of the extracellular availability of these essential amino acids present in YE. As it was observed in Figure 2B, when tryptophan was depleted from the fermentation broth, this strain decreased its $\mu$ even in the presence of $<70 \%$ residual glucose, showing that the availability of this amino acid is a determinant factor for growth capabilities of strain PB12.SA22 after $9 \mathrm{~h}$ of fermentation, although the strain could use additional (non-specified) carbohydrates supplied by YE (17.5\%) [36] or other amino acids as possible carbon sources.

Based on our GTA data, differential upregulation of genes encoding glycine transport components (operon proV $(W X)$ and the genes involved in the synthesis of serine from 3-P-glycerate and its subsequent transformation to glycine by upregulation of $g l y A$ and serA, no differential expression of $\operatorname{ser} B$ and $\operatorname{ser} C$ genes (Additional file 1) and the upregulation encoding genes for the GCV suggest an important role for these two amino acids in strain PB12.SA22 because they are most likely used additionally as protein components to yield $C_{1}$ units, which provide precursors for diverse important cellular process; indeed, it was reported that during growth on glucose, E. coli employs $\sim 15 \%$ of the carbon assimilated in serine and its metabolites, such as the synthesis of cysteine, phospholipids, and glycine, whereas glycine is used in the synthesis of purines and heme-containing compounds. $C_{1}$ units derived from serine and glycine are used in the synthesis of purines, histidine, thymine, pantothenate, and methionine and in the formylation of the aminoacylated initiator fMet-tRNA used to start translation in E. coli. In turn, these compounds are involved in other essential cellular process demanding the supply of $C_{1}$ units $[41,42]$, suggesting that particularly in the EXP/STA1 and EXP/STA2 comparisons $\mathrm{C}_{1}$ units derived from serine and glycine could be channeled for the biosynthesis of diverse cellular components used mainly for cellular maintenance of strain PB12.SA22 (Figure 3).

Interestingly, the genes encoding the complete biosynthetic pathway for arginine from glutamate ArgA, ArgB, ArgC, ArgD, ArgE, ArtI, ArgG and ArgH (argA, $\operatorname{argB}$, $\arg C, \arg D, \arg E, \arg F, \arg G$ and $\arg H$, respectively) and from bicarbonate to carbamoyl-phosphate (carAB) [17] were found to be upregulated in the STA1/STA2 comparison, whereas they were downregulated during the EXP phase (Additional file 1), suggesting an important role of this amino acid during the STA phase distinct 
Table 5 Average expression data of upregulated genes during STA1/STA2 comparison based on resultant FDR value from the RP analysis equal or less to 0.05 in compared growth phases during SA production cultures

\begin{tabular}{|c|c|c|c|c|}
\hline Gene & Locus & Protein name ${ }^{a}$ & Cellular function $\mathrm{GO}^{\mathrm{b}}$ & $\begin{array}{l}\text { Average } \\
\text { expression }\end{array}$ \\
\hline $\arg A$ & b2818 & Acetylglutamate synthase & Amino acid metabolism & 87.9837 \\
\hline $\arg B$ & b3959 & $\mathrm{N}$-acetylglutamate kinase & Amino acid metabolism & 45.8143 \\
\hline $\arg C$ & b3958 & N-acetylglutamylphosphate reductase & Amino acid metabolism & 53.4932 \\
\hline $\arg D$ & b3359 & N-succinyldiaminopimelate-aminotransferase/acetylornithine transaminase & Amino acid metabolism & 21.9053 \\
\hline $\arg E$ & b3957 & Acetylornithine deacetylase & Amino acid metabolism & 18.7485 \\
\hline $\arg G$ & b3172 & Argininosuccinate synthase & Amino acid metabolism & 65.2192 \\
\hline $\operatorname{argH}$ & b3960 & Argininosuccinate lyase & Amino acid metabolism & 23.7859 \\
\hline $\operatorname{argl}$ & b4254 & Ornithine carbamoyltransferase chain I & Amino acid metabolism & 33.2672 \\
\hline carA & b0032 & Polypeptide: CarA & Amino acid metabolism & 107.7785 \\
\hline $\operatorname{car} B$ & b0033 & Polypeptide: CarB & Amino acid metabolism & 23.9781 \\
\hline$i l v G \_1$ & b3767 & Acetolactate synthase II, large subunit, N-ter fragment & Amino acid metabolism & 75.4038 \\
\hline ilvG_2 & b3768 & Acetolactate synthase II, large subunit, N-ter fragment & Amino acid metabolism & 24.6648 \\
\hline$i / v M$ & b3769 & Polypeptide: IlvM & Amino acid metabolism & 16.9332 \\
\hline metE & b3829 & Cobalamin-independent homocysteine transmethylase & Amino acid metabolism & 59.0097 \\
\hline $\operatorname{ser} A$ & b2913 & a-Ketoglutarate reductase/D-3-phosphoglycerate dehydrogenase & Amino acid metabolism & 15.4266 \\
\hline ybas & b0485 & Glutaminase & Amino acid metabolism & 27.4637 \\
\hline fimC & b4316 & Periplasmic chaperone, required for type 1 fimbriae & Cell envelope & 20.5382 \\
\hline ydiQ & b1697 & Putative subunit of YdiQ-YdiR flavoprotein & Electron carrier activity & 32.4583 \\
\hline$y d i R$ & b1698 & Putative subunit of YdiQ-YdiR flavoprotein & Electron carrier activity & 32.3715 \\
\hline ydit & b1700 & Putative ferredoxin & Electron carrier activity & 28.0548 \\
\hline $\operatorname{arn} B$ & b2253 & UDP-L-Ara4O C-4' transaminase & Lipid metabolism & 20.7697 \\
\hline $\operatorname{arnc}$ & b2254 & Undecaprenyl phosphate-L-Ara4FN transferase & Lipid metabolism & 33.1058 \\
\hline yhiD & b3508 & Predicted $\mathrm{Mg}(2+)$ transport ATPase & Lipid metabolism & 52.2858 \\
\hline nary & b1467 & Nitrate reductase $Z, \beta$ subunit & Other metabolic process & 18.7104 \\
\hline narz & b1468 & Nitrate reductase $Z$, a subunit & Other metabolic process & 13.4094 \\
\hline yciE & b1257 & Conserved protein & Other metabolic process & 18.9020 \\
\hline ydis & b1699 & Putative flavoprotein & Other metabolic process & 20.0646 \\
\hline ygdl & b2809 & Putative lipoprotein & Out of OGs & 15.8477 \\
\hline$s / p$ & b3506 & Starvation lipoprotein & Out of OGs & 16.3895 \\
\hline ybar & b0453 & Predicted OM lipoprotein & Out of OGs & 31.4852 \\
\hline$y h j R$ & b3535 & Conserved protein & Out of OGs & 17.5298 \\
\hline yhiE & b3512 & GadE DNA-binding transcriptional activator & Regulatory & 224.6027 \\
\hline yhif & b3507 & Polypeptide: predicted DNA-binding transcriptional regulator & Regulatory & 33.7016 \\
\hline yhiW & b3515 & GadW DNA-binding transcriptional dual regulator & Regulatory & 33.4367 \\
\hline$y k f E$ & b0220 & Inhibitor of vertebrate C-type lysozyme & Regulatory & 40.8144 \\
\hline $\operatorname{gad} B$ & b1493 & Glutamate decarboxylase B & Stress response & 94.5462 \\
\hline hdeA & b3510 & HdeA dimer, inactive form of acid-resistance protein & Stress response & 125.3695 \\
\hline hdeB & b3509 & Acid stress chaperone & Stress response & 104.9129 \\
\hline hdeD & b3511 & Acid-resistance membrane protein & Stress response & 140.6337 \\
\hline katE & b1732 & Heme d synthase/hydroperoxidase & Stress response & 15.6533 \\
\hline cys D & b2752 & Polypeptide: CysD & Sulfur metabolism & 34.5193 \\
\hline cysH & b2762 & 3'-Phospho-adenylylsulfate reductase & Sulfur metabolism & 15.6801 \\
\hline hisP & b2306 & Lysine/arginine/ornithine $A B C$ transporter/histidine $A B C$ transporter - ATP binding subunit & Transport & 17.8485 \\
\hline
\end{tabular}


Table 5 Average expression data of upregulated genes during STA1/STA2 comparison based on resultant FDR value from the RP analysis equal or less to $\mathbf{0 . 0 5}$ in compared growth phases during SA production cultures (Continued)

\begin{tabular}{ccccc}
\hline potG & b0855 & Putrescine ABC transporter - ATP binding subunit & Transport & 18.0562 \\
artJ & b0860 & Arginine ABC transporter - periplasmic binding protein & Transport & 120.3908 \\
gadC & b1492 & Glutamic acid: 4-aminobutyrate antiporter & Transport & 28.9528 \\
hisM & b2307 & Lysine/arginine/ornithine ABC transporter/histidine ABC transporter - membrane subunit & Transport & 44.5442 \\
narU & b1469 & NarU MFS nitrate/nitrite antiporter & Transport & 62.1767 \\
ompC & b2215 & OMP C & Transport & 37.5373 \\
yggB & b2924 & Mechano sensitive channel MscS & Transport & 22.3863 \\
\hline
\end{tabular}

${ }^{\mathrm{a}}$ Retrieved from EcoCyc database, ${ }^{\mathrm{b}}$ Biological functions were assigned according to the EcoCyc database for E. coli strain MG1655 and broadly grouped on the basis of GO terms [17].

from its role as a protein component. Arginine is also available in the supernatant broth because it is also supplied by YE (3.03\%) [36]. This amino acid is transported by the arginine $\mathrm{ABC}$ transporter ArtPMQJI (argP, $\operatorname{argM}$, $\operatorname{argQ}$, $\operatorname{argJ}$ and $\operatorname{argI}$, respectively); however, among these genes, artI encodes the periplasmic binding component and is the unique found upregulated gene of this transporter, whereas the remaining genes were found without changes in their expression, suggesting that in addition to the upregulation of genes encoding the complete biosynthetic pathway for arginine from glutamate and bicarbonate, this amino acid is also transported from the fermentation broth during the STA phase. Arginine can be degraded by two pathways, the arginine succinyltransferase (AST) pathway yielding succinate, which enters to TCA, and the arginine decarboxylase/agmatinase pathway, which also yields succinate. This last pathway yields the intermediate putrescin, which connects arginine degradation with the biosynthetic pathways of the polyamines putrescine, spermidine, cadaverine and aminopropylcadaverine [17]. Interestingly, unlike E. coli K-12, wild-type E. coli strains are unable to use L-arginine as a carbon source, but they can use this amino acid as a nitrogen source $[47,48]$. Based on this evidence, our transcriptomic data suggest that arginine could be used by strain PB12.SA22 as a source of succinate to recycle C through TCA or as a source for polyamines during the STA phase for SA production. However, data mining of the RP method analysis for microarray data comparison between STA1/STA2 showed that none of the genes of the arginine AST degradation (operon astCADBE) and arginine decarboxylase/agmatinase (adiA, speB, speF, puuAP, puuDRCBE and $s a d$ ) pathways were significantly upregulated (Additional file 1). Polyamines are reported as necessary for cell growth because they are major polycations in cells, together with $\mathrm{Ca}^{2+}$ and $\mathrm{Mg}^{2+}$. Polyamines and $\mathrm{Mg}^{2+}$, which are present in higher free concentrations than $\mathrm{Ca}^{2+}$, can bind to intracellular polyanions such as nucleic acids and ATP to modulate their function [49]. Polyamines have also been associated with stabilizing membranes and stimulating several enzymes [17], and furthermore, spermidine was found to donate a portion of its molecule for the

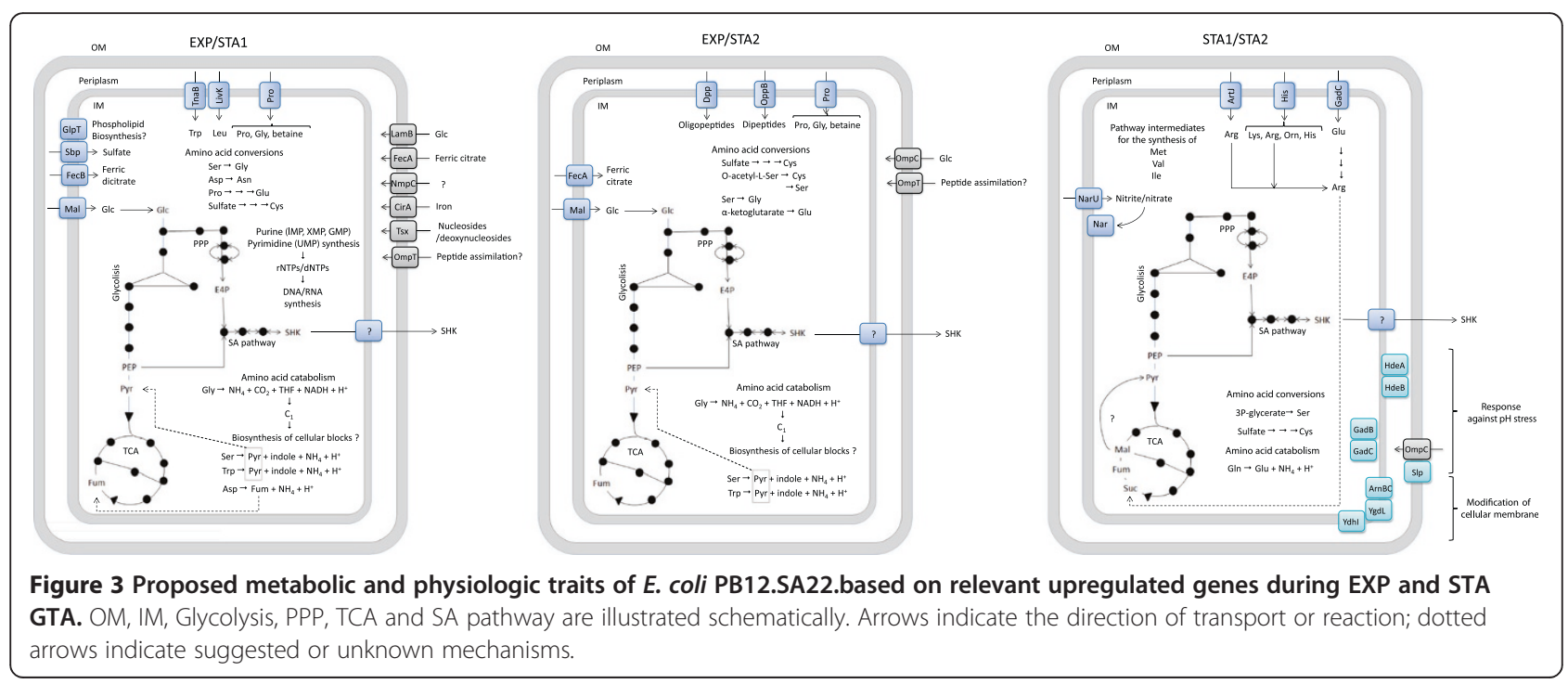


enzymatic biosynthesis of hypusine, a unique amino acid that plays a crucial role in cell proliferation [50]. Because strain PB12.SA22 ceased EXP growth by hour 9 of cultivation and entered a pseudo STA phase until the end of the fermentation, it is unlikely that arginine could be used as a polyamine precursor, suggesting that it could be used to supply succinate to TCA, through the gluconeogenic capabilities developed by strain PB12 [18,51], to make PEP available for use in SA production, particularly during the late STA phase in the absence of glucose (Figure 3).

\section{Possible associations between amino acid transport, catabolism and $\mathrm{pH}$ stress response}

Amino acids such as aspartate, serine and tryptophan could be used potentially by $E$. coli as carbon sources under certain growth conditions. Catabolism of aspartate by aspartate ammonia-lyase, AspA (aspA) yields Fum + ammonia $+\mathrm{H}^{+}$; catabolism of $\mathrm{L}$-serine by serine deaminase, $\mathrm{SdaB}(s d a B)$ yields $\mathrm{PYR}+\mathrm{ammonia}+\mathrm{H}^{+}$; whereas the catabolism of tryptophan catalyzed by tryptophanase (tnaA) yields PYR + ammonia + indole $+\mathrm{H}^{+}$. In turn, fumarate and PYR could fuel TCA or increase intracellular PYR availability, respectively [17]. However, amino acid deamination is a metabolic process displayed by E. coli to contend with alkaline stress that supplies carbon for bacterial growth under this condition, particularly when growing in complex peptide-rich media. As cell density increases, extracellular $\mathrm{pH}$ alkalinizes and released ammonia is deprotonated and volatilized, whereas the $\mathrm{C}$ skeleton is channeled into acids [52-54]. Based on our transcriptomic data showing the upregulation of genes such as tnaA, $a s p A$ and $s d a B$ during the EXP and STA phases, we propose that intracellular availability of amino acids such as aspartate, cysteine and tryptophan, either by importing them from the extracellular environment (as they are provided by YE) or by interconversion from other sources, e.g., cysteine from O-acetyl-L-serine by CysK (cysK) [17] (also upregulated during the EXP/STA2 comparison), have an important role in a possible cellular response of $E$. coli PB12.SA22 during SA production to extracellular alkalinization because upregulation of tnaA, asp $A$ and $s d a B$ suggests that their respective enzymes deaminate aspartate, cysteine and tryptophan to PYR or Fum. In addition to the upregulation of these genes, a previous report indicates that as a consequence of cellular exposure to neutral $\mathrm{pH}$ conditions, E. coli 3110 showed a higher expression of 93 genes (grouped as the neutral high expressed cluster showing highest expression at $\mathrm{pH} 7.0$ and lower expression at both $\mathrm{pH}$ extremes), including fecA, fecB, fecE, lamB, livK, malE, malF and malK [55]. Interestingly, all these genes were found to be upregulated in strain PB12.SA22 in the EXP/STA1 comparison, with exception of malE, which was also upregulated in the STA1/STA2 comparison.
Several genes encoding proteins involved in the AR in E. coli were found to be upregulated during the EXP and STA phases, including the chaperone-based AR proteins HdeA and HdeB, which belong to the hdeAB acid stress operon involved in the periplasmic acid stress response that prevent periplasmic-protein aggregation at acidic $\mathrm{pH}$; the IM protein HdeD ( $h d e D$ ), which is required for acid resistance [56], was found to be upregulated during the STA1/STA2 comparison, and GadB and GadC ( $\operatorname{gadBC}$ operon) were upregulated in the STA1/STA2 phases and are components of the Gad system (the glutamate decarboxylase system), the major AR system in E. coli under extreme acidic conditions [17]. GadB (together with GadA) are pyridoxal 5'-phosphate (PLP)dependent enzymes that convert glutamate to $\gamma$-amino butyric acid (GABA) and carbon dioxide in a reaction that consumes a cytoplasmic proton. GABA is transported out of the cell by the IM antiporter GadC in exchange for more extracellular glutamate [57], whereas GadW is a transcriptional dual regulator $y h i W$ or $\operatorname{gad} W)[17,57,58]$. Several regulatory genes of the Gad system $(\operatorname{gad} A, \operatorname{gadE}, \operatorname{gad} W$ and $\operatorname{gadX})$, as well as the chaperone-related genes $h d e A B D$, were placed in a unique cluster termed the acid fitness island [59], but interestingly, more genes in this island were found to participate in acid resistance, including the OM lipoprotein Slp $(s l p)$ and the transcriptional regulator YhiF (yhiF) (both genes were upregulated in the STA1/STA2 comparison in our transcriptomic study), which are required to protect cells against excreted toxic metabolites, including the accumulated anions of dissociated weak acids after growth at low $\mathrm{pH}$ such as lactate, succinate, and formate [57]. Additionally, GadE serves as the global transcriptional activator for many genes involved in stress response, glutamante biosynthesis, and in the biosynthesis of membrane components. Auto-induction of GadE requires the alternative sigma ${ }^{\mathrm{S}}$ factor responsible for the transcription of many genes in the STA phase and another unidentified factor, whereas P2 and P3 of gadE are activated by GadX (or YhiX) and GadW (or YhiW) during the STA phase [57].

The simultaneous upregulation of genes encoding proteins involved in acid $\mathrm{pH}$ stress response with the upregulation of catabolic amino acid pathway to revert an apparent alkalinization has been reported to have a common connection, the protein GadB [52]. As was discussed above, high extracellular $\mathrm{pH}$ induces transcription of several genes encoding enzymes generating ammonia, such as TnaA, CysK, SdaB and AsnA, by deaminating tryptophan, serine, cysteine and aspartate, respectively. Expression of $\operatorname{gadB}$ is controlled by sigma ${ }^{\mathrm{S}}$ during the STA phase in minimal growth medium; however, induction of this gene has been observed during growth in complex medium between $\mathrm{pH} 5.5$ and 8.0 [52,55,60]. Induction of 
the RpoS dependent- oxidative AR system has been reported due to the presence of glutamate in YE. Glutamate and glutamine appear to activate a preformed RpoSdependent system that is produced by entry into the STA phase [60]. According to this observation, simultaneous upregulation of the AR Gad system associated with the induction of genes involved in alkaline $\mathrm{pH}$ stress observed during SA production could be induced by the presence of glutamate in YE, which is transported by GadC. Additionally, upregulation of $h d e A B$ during the EXP/STA2 comparison can be explained by the inductor effect of glutamate because these genes are also activated by GadE and GadW [17].

It has been established that the $\mathrm{OM}$ envelope and the periplasmic space are cellular compartments exposed essentially to extracellular $\mathrm{pH}$ [52]. In bacterial strains used for metabolite production such as PB12.SA22, during SA production, it is not surprising that the periplasmic side of the IM, the periplasmic space and the inner side of the OM could be exposed to low acid stress because SA is exported from the cytoplasm and then diffuses into the extracellular environment; conversely, the external side of the OM could be exposed to low alkaline stress as a consequence of the addition of $\mathrm{NH}_{4} \mathrm{OH}$ to maintain fermentor $\mathrm{pH} \cong 7.0$. This supposition makes sense given the observed upregulation of genes involved in acid $\mathrm{pH}$ stress response, simultaneous with the upregulation of the deaminating amino acid pathway to reverse an apparent alkalinization during SA production by strain PB12.SA22 (Figure 3).

\section{Upregulation of genes involved in iron and sulfur transport and its metabolism}

Iron and sulfur seems to play an important physiological role during SA acid production by strain PB12.SA22 because some genes encoding transporters for these ions were found to be upregulated. Among these, $f e c B E$ was found to be upregulated in the EXP/STA1 comparison, and $f e c A$ was observed in the EXP/STA2 comparison. The $f e c A B C$ operon genes are located in the fecABCDE operon and encode the ferric citrate OMP FecA (fecA), the IM ferric dicitrate $A B C$ transporter $(f e c B)$, and the ATP binding component $(f e c E)$ [61]. Additionally, it was found to be upregulated in the EXP/STA1 comparison the OM receptor Cir ( $\operatorname{cir} A)$, a TonB dependent ironsiderophore complex involved in iron uptake and regulated by both cellular iron content and growth [62]. Regarding sulfur, the upregulation of the periplasmic binding protein (Sbp) sulfate/thiosulfate ANC transporter $(s b p)$ in the EXP/STA1 comparison was observed, which is associated with the transport both of sulfate and thiosulfate that are used as sulfur sources [63]. Finally, in the STA1/STA2 comparison, we also found that the genes narU, narZ and narY (part of the narUZYWV operon) were upregulated, which encode the nitrite/nitrate transporter (nar $U$ ) and the $\sigma$ and $\beta$ subunits of the IM located nitrite/nitrate reductase (narZ and narY, respectively).

Iron is essential for the growth of E. coli, as is emphasized by the variety of processes in which ironcontaining proteins take part, including their structural association to proteins involved in electron transport or playing important roles, particularly for iron-sulfur proteins involved in amino acid and pyrimidine biosynthesis (glutamate synthase, dihydroorotate dehydrogenase), and the TCA (aconitase, succinate dehydrogenase), as well as in electron transport (ferredoxin) and non-heme, noniron-sulfur proteins required for DNA synthesis (ribonucleotide reductase), protection from superoxide radicals (superoxide dismutase), and interestingly, aromatic amino acid biosynthesis (DAHP synthase) [64]. Exogenous ferric citrate (supplied in the fermentation broth for SA production as ammonium iron (III) citrate), is transported across the OM by FecA, and a signal is transmitted across the OM to the IM protein FecR, which transmits the signal across the IM, thereby activating (through the sigma ${ }^{70}$ factor) the cytoplasmic family protein FecI, which directs RNA polymerase to express the $f e c A B C D E$ operon $[17,61,65]$.

\section{Upregulation of genes involved in nucleotide/nucleoside transport and biosynthesis}

During the EXP/STA1 comparison, upregulation was observed for the gene encoding OMP Tsx (ts $x$ ), a protein that has been proposed to function in vivo as a pore that specifically facilitates the permeation of nucleosides and deoxynucleosides across the OM due to its specificity for free nucleobases or monophosphate nucleosides $[22,66]$. Regarding nucleotide/nucleoside metabolism, were found upregulated genes involved in pyrimidine ribonucleoside salvage, rihA and upp encoding ribonucleoside hydrolase 1 (pyrimidine-specific) and uracil phosphoribosyltransferase, respectively, which catalyze the sequential conversion of uridine $\rightarrow$ uracil $\rightarrow$ UMP [17]. Regarding pyrimidine ribonucleotide de novo biosynthesis, was found upregulated the gene $p y r B$ encoding the catalytic subunit of the aspartate carbamoyltransferase, an enzyme catalyzing the conversion of L-asparte + carbamoyl-P to N-carbamoyl-Laspartate in reactions involved in the biosynthesis of UMP in this pathway [17]. Finally, regarding the adenine and adenosine salvage pathway, upregulation was detected for the gpt gene, encoding xanthine-guanine phosphoribosyltransferase, which catalyzes the conversion of hypoxanthine to IMP, a common precursor for the guanosine and adenosine nucleotides in the de novo biosynthetic pathway [17].

Xanthine-guanine phosphoribosyltransferase is also involved in the xanthine and xanthosine salvage pathway, 
catalyzing the conversion of xanthine to XMP, which is then channeled to the purine nucleotide de novo biosynthesis pathway, and also catalyzes the transformation of guanine to GMP in the guanine and guanosine salvage pathway. GMP is, in turn, channeled to the guanosine nucleotide de novo biosynthesis pathway [17]. Additionally, upregulation was observed for guaC, encoding the GMP reductase, which catalyzes the conversion of GMP to IMP by a reductive deamination, and the $n r d A$ gene, encoding the $\alpha$-subunit dimer of the ribonucleoside diphosphate reductase 1 enzyme, which catalyzes the conversion of nucleotides to deoxynucleotides, an essential step during DNA synthesis, including its role in the chromosome replication and repair processes [17]. Data mining of the microarray expression comparison between the EXP/ STA1 phases showed no significant expression differences based on the FDR value $\leq 0.05$ for other genes involved in salvage pathway of pyrimidine ribonucleotides $(\mathrm{pyrH}, n d k$, pyrG, cmk) or for the pyrimidine de novo biosynthesis pathway (pyrC, pyrD, pyrE, pyrF, ndk or pyrG) (Additional file 1). Interestingly, $n r d A$ was found to be upregulated in the late STA phase, but no other genes involved in the purine and pyrimidine pathways discussed above were found to be significantly upregulated in the STA1/STA2 comparison.

All genes encoding enzymes related to the so-called nucleotide salvage pathways are involved in transformations of purine nucleotides derived from exogenous sources, whereas in the de novo pathways, they are synthesized from simpler precursors [67]. Our transcriptomic data, showed the upregulation of few genes encoding enzymes catalyzing reactions both in the de novo and salvage pathways involved in the synthesis of the purines IMP, XMP, GMP and the pyrimidine nucleotide UMP. Upregulation of the above described genes ensures the availability of rNTPs and dNTPs for RNA and DNA synthesis, respectively, from both purine (IMP, XMP, GMP) and pyrimidine (UMP) essential nucleotides during the growth stage of strain PB12.SA22 (Figure 3).

\section{Modification of the cellular membrane during the STA phase}

In the STA1/STA2 comparison, important differences were observed in the upregulation of several genes possibly involved in inner and $\mathrm{OM}$ structure modification and the response to diverse environmental processes with respect to the EXP/STA1 comparison. These include the $\operatorname{arn} B C$ genes encoding an undecaprenyl transferase involved in the modification of lipid A phosphates with 4-amino-4-deoxy-L-arabinose (L-Ara4N), which modifies the lipid composition of the outer face of the periplasmic membrane [68]; yciE, encoding YciE, a conserved protein of unknown function, which has been observed to be induced under osmotic stress imposed by $\mathrm{NaCl}$ in both aerobic and anaerobic conditions [69]; $y g d I$, encoding an IM putative lipoprotein [17]; slp, encoding a STA phase lipoprotein (Slp) that has been proposed to take part in acid resistance because its expression was observed when cells were grown in $\mathrm{pH} 5.5$ to 4.5 under conditions known to induce glutamate dependent acid resistance compared to $\mathrm{pH}$ 7.4, and also associated with YhiF to protect the cell against toxic metabolites [54]. Expression of $s l p$ was previously observed to increase 3-5-fold in the STA carbon starvation and was found to form homo-oligomer complexes tethered to the OM [70]. Other genes found to be upregulated were $y d h I$ (or $y h h E$ ), a putative ATPase transporter involved in high cell dependent acid resistance [71]; and the $o m p C$ gene, encoding OmpC. Although the possible role of OmpC in glucose transport during EXP growth was discussed above, expression of ompC and OmpC protein level have been demonstrated to also be influenced by a wide variety of environmental conditions including $\mathrm{pH}$, osmolarity, temperature, concentration of certain toxins, and growth phase [72]. OmpC and OmpF are reported as the major constituents of the $\mathrm{OM}$ in E. coli, accounting for approximately $2 \%$ of the total protein content of the cell [73]. The role of the OMPs in the modification of the $\mathrm{OM}$ has been previously reported, indicating that the OmpC/OmpT:OmpA ratio increased in total membrane protein analysis of an evolved E. coli resistance to increasing isobutanol concentrations correlating with upregulation of these genes, resulting in changes in the OM structure, accomplished with modification in membrane composition and peptidoglycan structure [74]. Interestingly, in support of our proposition regarding the possible role of those genes discussed in this section, particularly during the STA phase, cell resistance to lysis during the total RNA extraction procedure showed that PB12.SA22 modified its cellular surface properties because the protocol originally developed for successful total RNA extraction in the mid EXP phase $(5 \mathrm{~h})$ was modified for the extraction in the STA phases, thereby enhancing the cellular lysis step to yield a high amount of total RNA suitable for microarray analysis.

\section{Sigma factor regulatory networks controlling the expression profiles in the EXP and STA phases}

We constructed each regulatory network of the sigma factors controlling upregulated genes observed in EXP/ STA1, EXP/STA2 and STA1/STA2 comparisons. The sigma regulatory interactions were retrieved from the comparisons between the information stored in the Ecocyc and Regulon DB databases $[17,45]$. The comparisons show that the sigma ${ }^{70}$ (RpoD) was the main sigma factor targeting promoters for genes encoding amino acid 
metabolism, ATP biosynthetic/catabolic process, transport, electron carrier activity, nucleotide/nucleoside metabolism, cell envelope and stress response (Figure 4). However, although RpoD is the primary sigma factor during EXP growth, targeting a wide range of promoters that are essential for normal growth [75] as is shown in Figure 4, transcription of several upregulated genes were possibly controlled by sigma ${ }^{70}$ and at least one or two more sigma factors. However, the transcription of other sets of genes are possibly controlled only by alternative sigma factors, and interestingly, $17 \%, 16 \%$ and $18 \%$ of significantly upregulated genes during the EXP/STA1, EXP/STA2 and STA1/STA2 comparisons, respectively, are controlled by unspecified sigma factors.

Alternative sigma factors possibly controlling transcription of several genes simultaneously to sigma ${ }^{70}$ during EXP/STA1 comparison are sigma ${ }^{\mathrm{S}}$, sigma $^{32}$ and sigma ${ }^{19}$. Interestingly, the $f e c A, f e c B$ and $f e c E$ genes (encoding the ferric citrate OMP, the periplasmic binding protein and the ATP binding subunit of the dicitrate $\mathrm{ABC}$ transporter, respectively), are located in an operon with a promoter targeted by sigma ${ }^{19}$ controlling the expression of the $f e c A B C D$ operon genes, whereas the expression of the contiguous gene in the operon, fecE, is controlled by sigma ${ }^{70}$ and sigma ${ }^{19}$, thus suggesting, as discussed above, an important role for iron during EXP growth of strain PB12.SA22. During EXP/STA2 comparison, sigma ${ }^{\mathrm{S}}$ and sigma $^{70}$ were found to be controlling the expression of six genes involved in transport (membrane subunit of the glycine betaine/proline ABC transporter encoded in the operon proVWXX), acid stress response (hdeAB operon) and DNA binding transcriptional activators (yhiE, yhiW genes), respectively [17]. Data retrieved from the EcoCyc and Regulon DB databases suggested that during the STA phase (the STA1/ STA2 comparison), sigma ${ }^{70}$ was most likely associated with the transcription of 35 upregulated genes; however, in this comparison, it was proposed that the sigma factors ${ }^{54},{ }^{S},{ }^{32}$ and ${ }^{24}$ possibly simultaneously participated with sigma ${ }^{70} \mathrm{RpoD}$ in the co-transcription of 12 genes, including those involved in acid stress response $(\operatorname{gadBC}$, $h \operatorname{de} A B$ and $y h i D)$, nitrite/nitrate transport ( $y c i E$ ), osmotic stress response (yciE, katE) and DNA binding transcriptional activators ( $y h i E, y h i W$ genes) [17] (Figure 4).

Sigma $^{70}$ accounts for $60-95 \%$ of the total pool of cellular sigma factors during normal EXP growth [17]. Changes to typical growth conditions, such as heat shock, acid stress or growth into the STA even in rich broth, lead to the replacement of RpoD with other sigma factors such as RpoS, which is considered to be the master regulator of the general stress response in E. coli. RpoS is practically absent in rapidly growing cells but is strongly induced during entry into the STA phase and/or many other stress conditions and is essential for the expression of multiple stress resistances [76]. When wild-type E. coli is grown in glucoselimiting conditions and, interestingly, in $\mathrm{PTS}^{-}$strains such as PB12.SA22 parental strain PB12, transcription of several central metabolism and especially glycolytic genes turn on under the control of RpoS, which has been proposed as a second vegetative sigma factor with major impact not only on stress tolerance but on the entire cell physiology under non-optimal growth conditions $[77,78]$. However, the comparison of our transcriptomic data showed that the significantly upregulated genes across EXP/STA1, EXP/STA2 and STA1/STA2 that are controlled by RpoD average $71 \%$, and interestingly, in the comparison between EXP/STA2 and STA1/STA2, the sigma ${ }^{\mathrm{S}}$ factor was involved in the simultaneous upregulation of $22 \%$ of those genes controlled by sigma ${ }^{70}$.

Data mining of differentially expressed genes during all performed comparisons showed that all genes encoding sigma factors were not significantly up- or downregulated based on the FDR value $\leq 0.05$ (Additional file 1). This result suggests a relevant role for those positive or dual transcriptional factors targeting transcription initiation sites of upregulated genes.

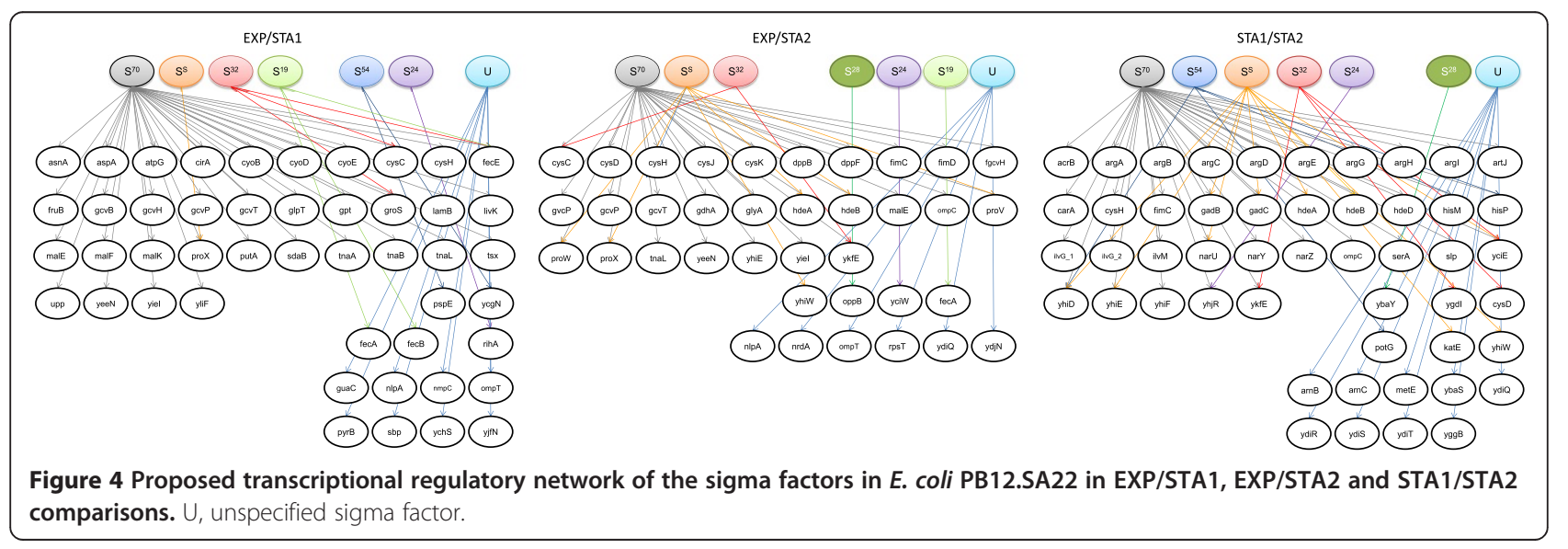




\section{Concluding remarks}

During batch cultures for SA production using complex fermentation broth (including $25 \mathrm{~g} / \mathrm{L}$ of glucose and $15 \mathrm{~g} / \mathrm{L}$ of YE), strain PB12.SA22 ceased EXP growth even in the presence of a high amount of residual glucose, indicating that growth was not associated with glucose consumption, depending to some extent of the availability of nutrients supplied by YE. This hypothesis was supported by the observation that EXP growth cessation is associated with the total consumption of available tryptophan in the supernatant, entering a STA-like phase where a brief increment in biomass was observed. During this stage, cells consumed residual glucose in the supernatant, suggesting that biomass produced during the EXP phase entered a resting cell-like condition producing SA. Because no changes were observed in the regulation of genes involved in CCM and the SA pathway between the EXP and STA phases, it is possible to propose that this strain transports and catabolizes extracellular glucose mainly for SA production in the STA phase until $26 \mathrm{~h}$ of cultivation, where glucose was completely consumed. Those metabolic capabilities regarding glucose catabolism and synthesis of precursors PEP and E4P for SA production could be a consequence of the permanent scavenging condition proposed previously for parental strain PB12, as a consequence of the inactivation of the PTS operon and diverse genetic changes developed during an evolutive adaptation process from which the PB12 strain was obtained $[18,79]$.

GTA of E. coli strain PB12.SA22 during SA production between the mid EXP phase $(5 \mathrm{~h})$, the early STA phase $(9 \mathrm{~h})$ and the late STA phase $(44 \mathrm{~h})$ showed no significant differences in absolute expression in genes encoding enzymes of CCM, glycolysis, the PPP, TCA, the glyoxilate shunt, acetate metabolism and gluconeogenic enzymes, such as those in the SA pathway. However, important differences were observed in the upregulation of genes encoding proteins involved in sugar, amino acid, nucleotide/nucleoside and iron and sulfur transport; metabolic processes, particularly amino acid catabolism and biosynthesis; nucleotide/nucleoside salvage; acid stress response; and the modification of the cell membrane in the EXP/STA1, EXP/STA2 and STA1/STA2 comparisons. Figure 3, shows a proposed metabolic model based on relevant upregulated genes observed during comparisons in strain PB12.SA22 during SA production in batch-fermentor cultures grown in a complex broth. During the EXP/STA1 comparison, strain PB12. SA22 has an important transport activity through OMPs and IM proteins that possibly transport glucose, sulfur, iron, amino acids, peptides and nucleotide/nucleosides whereas amino acid interconversion and catabolism process were maintained. In the EXP/STA2 comparison, an important reduction in transport activity was observed particularly for some amino acids and possibly peptides supplied by the YE, while important amino acid interconversion and catabolism processes, such as nucleotide/nucleoside biosynthesis, were maintained. In both comparisons, it is important to highlight the catabolism of amino acids such as serine, tryptophan and asparagine (EXP/STA1) and serine and tryptophan (EXP/ STA2), which results in PYR or Fum, and particularly the possible catabolism of glycine through the GCV, suggesting the possibility that PYR and Fum could be channeled to the CCM, whereas the catabolism of cysteine could result in the availability of $\mathrm{C}_{1}$ units for the biosynthesis of cellular blocks. Finally, during the STA1/STA2 comparison, only the transport of arginine, glutamic acid, and nitrite/nitrate and the biosynthesis of arginine from glutamic acid were observed. The availability of arginine and its possible catabolism could yield succinate, which could be channeled to the TCA. As was discussed, glucose is completely consumed at $26 \mathrm{~h}$ of cultivation, but SA accumulation continued until the end of fermentation. The results suggest how strain PB12.SA22 continues producing SA during the late STA phase. Even if the catabolism of arginine could fuel carbon into TCA and, possibly, the gluconeogenic capabilities of this strain could supply PYR and PEP, the availability of E4P becomes a limiting resource for DAPH synthesis and the subsequent accumulation of SA. Another important group of genes upregulated in the STA1/STA2 comparison are possibly involved in the cellular response to $\mathrm{pH}$ stress genes $(\operatorname{gadB}, \operatorname{gadC}, h d e A, h d e B)$ and several genes encoding proteins possibly involved in both outer and IM modifications as a response to environmental conditions imposed on the cell at the end of the fermentation.

Finally, the network reconstruction based on different sigma factors controlling the expression of upregulated genes of each condition showed that even sigma ${ }^{\mathrm{S}}$ has been proposed to be the master regulator of the STA, and sigma ${ }^{70}$ also plays an important role in controlling some upregulated genes with no alternative reported sigma factor or any sharing its regulatory region with a sigma ${ }^{\mathrm{S}}$ promoter or an alternative sigma factor. This sharing is an important property of regulatory networks, which gives them plasticity to adapt to different environmental conditions.

\section{Methods}

\section{Bacterial strain and growth conditions}

The SA-producing strain PB12.SA22 (PTS ${ }^{-}$AaroK $\triangle$ aroL pTOPOaroBaroE, pJLBaroG ${ }^{\mathrm{fbr}}$ tktA) [10] was shake-flask cultured in $125 \mathrm{~mL}$ baffled flasks containing $10 \mathrm{~mL}$ of LuriaBertani broth supplemented with $30 \mu \mathrm{g} / \mathrm{mL}$ of kanamycin, $15 \mu \mathrm{g} / \mathrm{mL}$ of gentamycin, $20 \mu \mathrm{g} / \mathrm{mL}$ of chloramphenicol, 
and $30 \mu \mathrm{g} / \mathrm{mL}$ of tetracycline. Cultures were incubated overnight in a shaker (New Brunswick Scientific, Edison, USA) at $37^{\circ} \mathrm{C}, 300 \mathrm{rpm}$. An aliquot of $150 \mu \mathrm{L}$ of this culture was used to inoculate a $250 \mathrm{~mL}$ baffled flask with $50 \mathrm{~mL}$ of fermentation medium containing $25 \mathrm{~g} / \mathrm{L}$ of glucose and $15 \mathrm{~g} / \mathrm{L}$ of $\mathrm{YE}[8,10]$. Biomass concentration was determined, and calculations were performed to adjust inoculum size at $\mathrm{OD}_{600 \mathrm{~nm}}=0.35$ and to inoculate batch cultures (by triplicate) in an Applikon autoclavable glass Bio Reactor one L fermentor with a $500 \mathrm{~mL}$ working volume of fermentation medium supplemented with required antibiotics. Fermentor vessels were connected to an Applikon ADI 1010 BioController and ADI 1025 controllers to monitor temperature, $\mathrm{pH}$, impeller speed and $\mathrm{DO}$. Batch fermentations were run for $50 \mathrm{~h}$ at $37^{\circ} \mathrm{C}, \mathrm{pH} 7.0$ (maintained by addition of $3.0 \%$ of $\mathrm{NH}_{4} \mathrm{OH}$ ). Impeller speed of no less than $500 \mathrm{rpm}$ was used to maintain DO levels at $20 \%$ air saturation [80]. Gene-carrying plasmids were induced by adding $0.1 \mathrm{mM}$ of isopropyl $\beta$-D-1thiogalactopyranoside.

\section{Analytical procedures}

Biomass concentrations were monitored each hour during the first eight $\mathrm{h}$ of cultivation. After this point, concentrations were monitored every six $h$ until the end of the fermentation $(50 \mathrm{~h})$. Triplicated samples $(1.5 \mathrm{~mL})$ were withdrawn from each reactor and $\mathrm{OD}_{600 \mathrm{~nm}}$ was determined spectrophotometrically (Beckman DUR-70 Spectrophotometer). Supernatant samples for the determination of SA, DHP, DHS, and GA were prepared by centrifuging one $\mathrm{mL}$ of fermented broth at $12,000 \mathrm{rpm}$ for $1 \mathrm{~min}$. To remove any residual cell in the supernatant, the centrifuged samples were filtered through $0.45 \mu \mathrm{M}$ nylon membranes. SA, DHS, and GA concentrations were determined by HPLC as described previously [10], whereas DAHP concentrations were determined by the thiobarbituric acid assay [81]. Because this method does not distinguish between DAHP and DAH, in this work, DAHP levels corresponded to the sum of both compounds [82]. Glucose concentration was assessed by a biochemical analyzer (YSI 2700 Select). Aromatic amino acids phenylalanine, tyrosine and tryptophan, present in culture supernatants, were quantified using a Phenomenex Synergy Hydro RP18 column (150 by $4.6 \mathrm{~mm} ; 4 \mu \mathrm{m})$ attached to an Agilent 1100 HPLC system (Agilent Technologies). Running conditions were as follows: mobile phase, $0.2 \%$ of trifluoroacetic acid $40 \%$ of methanol; flow, $0.5 \mathrm{~mL} / \mathrm{min}$. Detection was performed by photodiode array at $280_{\mathrm{nm}}$ [82].

The $\mu$ and the $q s$ were calculated during the EXP growth phase. qs was calculated as the differential change in $\mathrm{S}$, with time $(\mathrm{t})$ normalized to the biomass concentration $\left(q s=\frac{\mu}{Y x / s}\right)$. A predetermined correlation factor $\left(1 \mathrm{OD}_{600 \mathrm{~nm}}\right.$ corresponded to $0.37 \mathrm{~g} / \mathrm{L}$ of $\left.\mathrm{DW}\right)$ was used to transform $\mathrm{OD}_{600 \mathrm{~nm}}$ values into cell concentrations for $q s$ and $\mu$ calculation.

TACY determinations were based on the combined molar yields of DAHP, DHS, SA, and GA [10]. Results were reported as the average of triplicated samples with their associated standard deviation.

\section{RNA extraction procedures}

One aliquot of $5 \mathrm{~mL}$ from each of three fermentor cultures performed were collected at the middle of the EXP growth phase $\left(5 \mathrm{~h}, \mathrm{DO}_{600 \mathrm{~nm}}=7.00\right)$, the early STA state $\left(9 \mathrm{~h}, \mathrm{DO}_{600 \mathrm{~nm}}=13.00\right)$ and the late STA state $(44 \mathrm{~h}$, $\mathrm{DO}_{600 \mathrm{~nm}}=15.2$ ) (resulting in triplicate samples for each time), and transferred to a $15-\mathrm{mL}$ Falcon tube containing $500 \mu \mathrm{L}$ of RNA later solution (Ambion). Total RNA extraction was performed using a modification of the previously reported hot phenol-based procedure. Previous methodology was used successfully for total RNA extraction from cultures of E. coli JM101, and its PTS ${ }^{-}$derivative PB11 and PB12 strains, grown in batchfermentor cultures in minimal M9 medium and collected at $\mathrm{DO}_{600} \mathrm{~nm}=1.0$ [18]; however, direct application of this methodology to biomass collected from cultures of strain PB12.SA22 for SA production in a complex medium resulted in poor total RNA yield, particularly in samples collected during STA. To obtain total RNA of high quality (non-degraded and with high absorbance $\mathrm{DO}_{260 / 280}$ and $\mathrm{DO}_{230 / 260}$ ratios) and concentration required to perform successful GTA, the original RNA extraction procedure was modified and optimized. The integrity of extracted total RNA was evaluated by agarose gel electrophoresis, and quality was evaluated by determination of concentration and the $\mathrm{DO}_{260 / 280}$ and $\mathrm{DO}_{260 / 230}$ ratios in a Nanodrop-2000c spectrophotometer (Thermo Scientific). Samples were adjusted to a final concentration of total $\mathrm{RNA}=1 \mu \mathrm{g} / \mu \mathrm{L}$. Aliquots of $20 \mu \mathrm{L}$ of total RNA were shipped to the Precision Biomarker company for microarray experiments (www. precisionbiomarker.com).

\section{Microarray design, experiments and data analysis}

Total RNA extracted from each samples withdrawn at 5, 9 and $44 \mathrm{~h}$ from triplicated fermentor cultures, were entirely processed by Precision Biomarker. Sample preparation and processing included cDNA synthesis, cDNA fragmentation, and the preparation of the hybridization mixture, hybridization with the Affymetrix GeneChip ${ }^{\circ}$ E. coli Genome 2.0 (Affymetrix), washing, staining, and scanning of the microarrays, which were all performed according to the manufacturers' procedures. Raw data acquisition and gene expression data analysis were performed by Precision Biomarker using background correction, normalization and summarization. The resulting 
databases corresponding to the analyzed samples were analyzed in our laboratory by retrieving expression data from the array of E. coli MG1655, including in the Affymetrix GeneChip ${ }^{\circ}$ E. coli Genome 2.0. Average data of triplicates from each growth phase sampled were used to calculate the relative expression value between EXP relative to STA1 (EXP/STA1 $\left(2^{\wedge}\right.$ (EXP-STA1) $)$, STA1 relative to STA2 (STA1/STA2 $\left(2^{\wedge \text { (STA1-STA2) }}\right)$ and EXP relative to STA2 $\left(2^{\wedge(\text { EXP-STA2) })}\right.$. The resulting databases were formatted using a Perl language program from http://www.gla.ac.uk/schools/ computing/?CFID=21255484\&CFTOKEN=17693561 for analysis by the rank product method to identify differentially expressed (upregulated or downregulated) genes $[15,16]$.

\section{Additional file}

Additional file 1: Differentially upregulated and downregulated genes during EXP/STA1, EXP/STA2 and STA1/STA2 comparisons based on the application of the RP defined by a FDR value $\leq 0.05$.

\section{Abbreviations}

$\mu$ : Specific growth rate; AR: Acid response; $C_{1}$ : One-carbon units; CCM: Central carbon metabolism; CHA: Chorismic acid; DAHP: 3-Deoxy-Darabinoheptulosonate 7-phosphate; DAHQ: 3-Dehydroquinic acid; DHQ: Dehydratase 3-Dehydroquinate dehydratase; DHQ: Synthase 3-Dehydroquinate synthase; DHS: 3-Dehydroshikimic acid; DO: Dissolved oxygen; DW: Dry weight; E4P: Erythrose 4-phosphate; EPSP: 5-Enolpyruvylshikimate-3-phosphate; EXP: Exponential growth phase; fbr: Feedback resistant; FDR: False discovery rate; Fum: Fumarate; GA: Gallic acid; GMP: Guanosine-monophosphate; GO: Gene ontology; GTA: Global transcriptomic analysis; IM: Inner or cellular membrane; IMP: Inosine-5'phosphate; OAA: Oxaloacetate; OD: Optical density; OM: Outer membrane; OMP: Outer membrane porin; OSP: Oseltamivir phosphate; PEP: Phosphoenol pyruvate; PPP: Pentose-phosphate pathway; PTS: Phosphoenolpyruvate: carbohydrate phosphotransferase system; $q_{s}$ : Glucose consumption rate; RP: Rank products; S3P: Shikimate-3-phosphate; SA: Shikimic acid; STA: Stationary phase; TACY: Total aromatic compounds yield; TCA: Tricarboxylic acid cycle; UMP: Uridine-5'-phosphate; XMP: Xanthosine-5'-phosphate; YE: Yeast extract.

\section{Competing interests}

The authors declare that they have no competing interests.

\section{Authors' contributions}

$L C T, R M G, F B$ and $A E$ participated in the design of this study. $L C T$ and $L M M$ developed the total RNA extraction methodology. RA was involved in fermentations. $L C T$ and RMG analysed the microarray data analysis. AE, FB, RMG, GG and LCT participated in the analysis of the results, as well as in writing and critical review of the manuscript. All authors have read and approved the manuscript.

\section{Acknowledgements}

We thank Georgina Hernández Chávez for HPLC analysis support. This work was supported by FONSEC Salud-CONACyT grant 126793, CONACYT Ciencia Básica 105782, 106428 and DGAPA-PAPIIT, UNAM IN205811 and IN206812-2.

\footnotetext{
Author details

'Departamento de Ingeniería Celular y Biocatálisis, Instituto de Biotecnología, Universidad Nacional Autónoma de México, Av. Universidad 2001, Col. Chamilpa, Cuernavaca, Morelos 62210, México. ${ }^{2}$ Departamento de Microbiología Molecular, Instituto de Biotecnología, Universidad Nacional Autónoma de México, Av. Universidad 2001, Col. Chamilpa, Cuernavaca, Morelos 62210, México.
}

Received: 13 December 2013 Accepted: 18 February 2014 Published: 21 February 2014

\section{References}

1. Herrmann KM, Weaver LM: The shikimate pathway. Annu Rev Plant Physiol Plant Mol Biol 1999, 50:473-503

2. Richards TA, Dacks JB, Campbell SA, Blanchard JL, Foster PG, McLeod R, Roberts CW: Evolutionary origins of the eukaryotic shikimate pathway: gene fusions, horizontal gene transfer, and endosymbiotic replacements. Eukaryot Cell 2006, 5:1517-1531.

3. Krämer M, Bongaerts J, Bovenberg R, Kremer S, Müller U, Orf S, Wubbolts M, Raeven $\mathrm{L}$ : Metabolic engineering for microbial production of shikimic acid. Metab Eng 2003, 5:277-283.

4. Ghosh S, Chisti Y, Banerjee UC: Production of shikimic acid. Biotechnol Adv 2012, 30:1425-1431.

5. Tripathi P, Rawat G, Yadav S, Saxena RK: Fermentative production of shikimic acid: a paradigm shift of production concept from plant route to microbial route. Bioprocess Biosyst Eng 2013, 11:1665-1673.

6. Abbott A: Avian flu special: what's in the medicine cabinet? Nature 2005, 435:407-409.

7. Luo M: Structural biology: antiviral drugs fit for a purpose. Nature 2006, 443:37-38.

8. Chandran SS, Yi J, Draths KM, von Daeniken R, Weber W, Frost JW: Phosphoenolpyruvate availability and the biosynthesis of shikimic acid. Biotechnol Prog 2003, 19:808-814

9. Johansson L, Lindskog A, Silfversparre G, Cimander C, Nielsen KF, Lidén G: Shikimic acid production by a modified strain of E. coli (W3110.shik1) under phosphate-limited and carbon-limited conditions. Biotechnol Bioeng 2005, 92:541-552.

10. Escalante A, Calderón R, Valdivia A, De AR, Hernández G, Ramírez OT, Gosset G, Bolívar F: Metabolic engineering for the production of shikimic acid in an evolved Escherichia coli strain lacking the phosphoenolpyruvate: carbohydrate phosphotransferase system. Microb Cell Factories 2010, 9:21.

11. Chen K, Dou J, Tang S, Yang Y, Wang H, Fang H, Zhou C: Deletion of the aroK gene is essential for high shikimic acid accumulation through the shikimate pathway in E. coli. Bioresour Technol 2012, 119:141-147.

12. Rodriguez A, Martínez JA, Báez-Viveros JL, Flores N, Hernández-Chávez G, Ramírez OT, Gosset G, Bolivar F: Constitutive expression of selected genes from the pentose phosphate and aromatic pathways increases the shikimic acid yield in high-glucose batch cultures of an Escherichia coli strain lacking PTS and pykF. Microb Cell Factories 2013, 12:86.

13. Cui Y-Y, Ling C, Zhang Y-Y, Huang J, Liu J-Z: Production of shikimic acid from Escherichia coli through chemically inducible chromosomal evolution and cofactor metabolic engineering. Microb Cell Factories 2014, 13:21.

14. Johansson L, Lidén G: Transcriptome analysis of a shikimic acid producing strain of Escherichia coli W3110 grown under carbon- and phosphate-limited conditions. J Biotechnol 2006, 126:528-545.

15. Breitling R, Armengaud P, Amtmann A, Herzyk P: Rank products: a simple, yet powerful, new method to detect differentially regulated genes in replicated microarray experiments. FEBS Lett 2004, 573:83-92.

16. Hong F, Breitling R: A comparison of meta-analysis methods for detecting differentially expressed genes in microarray experiments. Bioinformatics 2008, 24:374-382.

17. Keseler IM, Mackie A, Peralta-Gil M, Santos-Zavaleta A, Gama-Castro S, Bonavides-Martínez C, Fulcher C, Huerta AM, Kothari A, Krummenacker M, Latendresse M, Muñiz-Rascado L, Ong Q, Paley S, Schröder I, Shearer AG, Subhraveti P, Travers M, Weerasinghe D, Weiss V, Collado-Vides J, Gunsalus RP, Paulsen I, Karp PD: EcoCyc: fusing model organism databases with systems biology. Nucleic Acids Res 2013, 41(Database issue):D605-D612

18. Flores N, Flores S, Escalante A, de Anda R, Leal L, Malpica R, Georgellis D, Gosset G, Bolívar F: Adaptation for fast growth on glucose by differential expression of central carbon metabolism and gal regulon genes in an Escherichia coli strain lacking the phosphoenolpyruvate: carbohydrate phosphotransferase system. Metab Eng 2005, 7:70-87.

19. Báez-Viveros J, Flores N, Juárez K, Castillo-España P, Bolivar F, Gosset G: Metabolic transcription analysis of engineered Escherichia coli strains that overproduce L-phenylalanine. Microb Cell Factories 2007, 6:30.

20. Ferenci T: Hungry bacteria-definition and properties of a nutritional state. Environ Microbiol 2001, 3:605-611.

21. Bordignon $\mathrm{E}$, Grote $\mathrm{M}, \mathrm{Sch}$ eider $\mathrm{E}$ : The maltose ATP-binding cassette transporter in the 21st century - towards a structural dynamic perspective on its mode of action: maltose $A B C$ transporter in the 21 st century. Mol Microbiol 2010, 77:1354-1366. 
22. Yamashita S, Buchanan SK: Module 3.3.1. Solute and ion transport: outer membrane pores and receptors. In Escherichia Coli Salmonella Cell Mol Biol. Edited by Böck A, Curtiss R III, Kaper J, Karp PD, Neidhardt F, Nystrom T, Squires C, Ussery D. Washington, DC: ASM Press; 2010.

23. Zhang H-K, Lu H, Wang J, Liu G-F, Zhou J-T, Xu M-Y: Global transcriptome analysis of Escherichia coli exposed to immobilized anthraquinone2-sulfonate and azo dye under anaerobic conditions. Appl Microbiol Biotechnol 2013, 97:6895-6905.

24. Lemieux MJ, Huang Y, Wang D-N: Glycerol-3-phosphate transporter of Escherichia coli: structure, function and regulation. Res Microbiol 2004, 155:623-629.

25. Yanofsky C, Horn V, Gollnick P: Physiological studies of tryptophan transport and tryptophanase operon induction in Escherichia coli. J Bacterio/ 1991, 173:6009-6017.

26. Payne JW, Morley JS, Armitage P, Payne GM: Transport and hydrolysis of antibacterial peptide analogues in Escherichia coli: backbone-modified aminoxy peptides. J Gen Microbiol 1984, 130:2253-2265.

27. Olson ER, Dunyak DS, Jurss LM, Poorman RA: Identification and characterization of $\mathrm{dppA}$, an Escherichia coli gene encoding a periplasmic dipeptide transport protein. J Bacterio/ 1991, 173:234-244.

28. Guyer CA, Morgan DG, Staros JV: Binding specificity of the periplasmic oligopeptide-binding protein from Escherichia coli. J Bacteriol 1986, 168:775-779.

29. Goodell EW, Higgins CF: Uptake of cell wall peptides by Salmonella typhimurium and Escherichia coli. J Bacteriol 1987, 169:3861-3865.

30. Hiles ID, Gallagher MP, Jamieson DJ, Higgins CF: Molecular characterization of the oligopeptide permease of Salmonella typhimurium. J Mol Biol 1987, 195:125-142

31. Angelopoulos N, Kallaras C, Apostolakis M: Effects of intracerebroventricular administration of atrial natriuretic peptide on subcortical EEG activity in conscious rabbits. Exp Brain Res Exp Hirnforsch Expérimentation Cérébrale 1996, 108:427-432.

32. Lucht JM, Bremer E: Adaptation of Escherichia coli to high osmolarity environments: osmoregulation of the high-affinity glycine betaine transport system proU. FEMS Microbiol Rev 1994, 14:3-20.

33. Verheul A, Wouters JA, Rombouts FM, Abee T: A possible role of ProP, ProU and CaiT in osmoprotection of Escherichia coli by carnitine. J Appl Microbiol 1998, 85:1036-1046.

34. Lamark T, Styrvold OB, Strøm AR: Efflux of choline and glycine betaine from osmoregulating cells of Escherichia coli. FEMS Microbiol Lett 1992 75:149-154

35. Moreau PL: The lysine decarboxylase CadA protects Escherichia coli starved of phosphate against fermentation acids. J Bacteriol 2007 189:2249-2261.

36. Zimbro MJ, Power DA: Difco \& BBL Manual: Manual of Microbiological Culture Media. Sparks, MD: Becton Dickinson and Co.; 2009

37. Kredich NM, Tomkins GM: The enzymic synthesis of L-cysteine in Escherichia coli and Salmonella typhimurium. J Biol Chem 1966, 241:4955-4965.

38. Fimmel AL, Loughlin RE: Isolation and characterization of cysK mutants of Escherichia coli K12. J Gen Microbiol 1977, 103:37-43.

39. Boronat A, Britton P, Jones-Mortimer MC, Kornberg HL, Lee LG, Murfitt D, Parra F: Location on the Escherichia coli genome of a gene specifying O-acetylserine (Thiol)-lyase. J Gen Microbiol 1984, 130:673-685.

40. Flint DH, Tuminello JF, Miller TJ: Studies on the synthesis of the Fe-S cluster of dihydroxy-acid dehydratase in Escherichia coli crude extract isolation of $\mathrm{O}$-acetylserine sulfhydrylases $\mathrm{A}$ and $\mathrm{B}$ and $\mathrm{B}$-cystathionase based on their ability to mobilize sulfur from cysteine and to participate in Fe-S cluster synthesis. J Biol Chem 1996, 271:16053-16067.

41. Stauffer GV: Biosynthesis of serine, glycine, and one-carbon units. In Escherichia coli Salmonella Cell Mol Biol. 2nd edition. Edited by Neidhardt F. Washington, DC: ASM Press; 2005:506-513.

42. Okamura-lkeda K, Ohmura Y, Fujiwara K, Motokawa Y: Cloning and nucleotide sequence of the $g c v$ operon encoding the Escherichia coli glycine-cleavage system. Eur J Biochem 1993, 216:539-548.

43. Ghrist AC, Stauffer GV: The Escherichia coli glycine transport system and its role in the regulation of the glycine cleavage enzyme system. Microbiology 1995, 141:133-140.

44. Thoden JB, Raushel FM, Benning MM, Rayment I, Holden HM: The structure of carbamoyl phosphate synthetase determined to $2.1 \AA$ resolution. Acta Crystallogr D Biol Crystallogr 1999, 55:8-24.
45. Salgado H, Peralta-Gil M, Gama-Castro S, Santos-Zavaleta A, Muniz-Rascado L, Garcia-Sotelo JS, Weiss V, Solano-Lira H, Martinez-Flores I, Medina-Rivera A, Salgado-Osorio G, Alquicira-Hernandez S, Alquicira-Hernandez K, Lopez-Fuentes A, Porron-Sotelo L, Huerta AM, Bonavides-Martinez C, Balderas-Martinez YI, Pannier L, Olvera M, Labastida A, Jimenez-Jacinto V, Vega-Alvarado L, del Moral-Chavez V, Hernandez-Alvarez A, Morett E, Collado-Vides J: RegulonDB v8.0: omics data sets, evolutionary conservation, regulatory phrases, cross-validated gold standards and more. Nucleic Acids Res 2012, 41:D203-D213.

46. Dailey FE, Cronan JE: Acetohydroxy acid synthase I, a required enzyme for isoleucine and valine biosynthesis in Escherichia coli K-12 during growth on acetate as the sole carbon source. J Bacterio/ 1986, 165:453-460.

47. McFalland E, Newman E: Amino acids as carbon sources. In Escherichia coli Salmonella Cell Mol Biol. 2nd edition. Edited by Neidhardt F. Washington, DC: ASM Press; 2005:358-379.

48. Cunin R, Glansdorff N, Piérard A, Stalon V: Biosynthesis and metabolism of arginine in bacteria. Microbiol Rev 1986, 50:314-352.

49. Igarashi K, Kashiwagi K: Polyamine transport in bacteria and yeast. Biochem J 1999, 344:633-642.

50. Vassylyev DG: Crystal structure and mutational analysis of the Escherichia coli putrescine receptor. structural basis for substrate specificity. J Biol Chem 1998, 273:17604-17609.

51. Sigala JC, Flores S, Flores N, Aguilar C, de Anda R, Gosset G, Bol\&iacute;var F: Acetate metabolism in Escherichia coli strains lacking phosphoenolpyruvate: carbohydrate phosphotransferase system; evidence of carbon recycling strategies and futile cycles. J Mol Microbiol Biotechnol 2009, 16:224-235.

52. Stancik LM, Stancik DM, Schmidt B, Barnhart DM, Yoncheva YN, Slonczewski $J \mathrm{~L}$ : $\mathrm{pH}$-Dependent expression of periplasmic proteins and amino acid catabolism in Escherichia coli. J Bacteriol 2002, 184:4246-4258.

53. Padan $\mathrm{E}$, Bibi $\mathrm{E}$, Ito $\mathrm{M}$, Krulwich TA: Alkaline $\mathrm{pH}$ homeostasis in bacteria: new insights. Biochim Biophys Acta BBA - Biomembr 2005, 1717:67-88.

54. Tucker DL, Tucker N, Conway T: Gene expression profiling of the $\mathrm{pH}$ response in Escherichia coli. J Bacteriol 2002, 184:6551-6558.

55. Maurer LM, Yohannes E, Bondurant SS, Radmacher M, Slonczewski JL: pH regulates genes for flagellar motility, catabolism, and oxidative stress in Escherichia coli K-12. J Bacteriol 2004, 187:304-319.

56. Masuda N, Church GM: Regulatory network of acid resistance genes in Escherichia coli. Mol Microbiol 2003, 48:699-712.

57. Zhao B, Houry WA: Acid stress response in enteropathogenic gammaproteobacteria: an aptitude for survival. Biochem Cell Biol 2010, 88:301-314.

58. Kern R, Malki A, Abdallah J, Tagourti J, Richarme G: Escherichia coli HdeB is an acid stress chaperone. J Bacteriol 2006, 189:603-610.

59. Hommais F: GadE (YhiE): a novel activator involved in the response to acid environment in Escherichia coli. Microbiology 2004, 150:61-72.

60. Castanie-Cornet M-P, Penfound TA, Smith D, Elliott JF, Foster JW: Control of acid resistance in Escherichia coli. J Bacteriol 1999, 181:3525-3535.

61. Härle C, Kim I, Angerer A, Braun V: Signal transfer through three compartments: transcription initiation of the Escherichia coli ferric citrate transport system from the cell surface. EMBO J 1995, 14:1430.

62. Griggs DW, Tharp BB, Konisky J: Cloning and promoter identification of the iron-regulated cir gene of Escherichia coli. J Bacteriol 1987, 169:5343-5352.

63. Sirko A, Zatyka M, Sadowy E, Hulanicka D: Sulfate and thiosulfate transport in Escherichia coli K-12: evidence for a functional overlapping of sulfate- and thiosulfate-binding proteins. J Bacteriol 1995, 177:4134-4136.

64. Earhart CF: Uptake and metabolism of iron and molybdenum. In Escherichia coli Salmonella Cell Mol Biol. Volume 1. 2nd edition. Edited by Neidhardt F. Washington, DC: ASM Press; 2005:1075-1090.

65. Enz S, Mahren S, Stroeher UH, Braun V: Surface signaling in ferric citrate transport gene induction: interaction of the FecA, FecR, and Fecl regulatory proteins. J Bacterio/ 2000, 182:637-646.

66. Maier C, Bremer E, Schmid A, Benz R: Pore-forming activity of the Tsx protein from the outer membrane of Escherichia coli. Demonstration of a nucleoside-specific binding site. J Biol Chem 1988, 263:2493-2499.

67. Zalkin H, Nygaard P: Biosynthesis of purine nucleotides. In Escherichia coli Salmonella Cell Mol Biol. Volume 1. 2nd edition. Edited by Neidhardt F. Washington, DC: ASM Press; 2005:561-579.

68. Breazeale SD, Ribeiro AA, Raetz CRH: Oxidative decarboxylation of UDPglucuronic acid in extracts of polymyxin-resistant Escherichia coli origin 
of lipid a species modified with 4-amino-4-deoxy-l-arabinose. J Biol Chem 2002, 277:2886-2896.

69. Weber A, Kögl SA, Jung K: Time-dependent proteome alterations under osmotic stress during aerobic and anaerobic growth in Escherichia coli. J Bacteriol 2006, 188:7165-7175.

70. Stenberg F, Chovanec P, Maslen SL, Robinson CV, llag LL, von Heijne G, Daley DO: Protein complexes of the Escherichia coli cell envelope. J Biol Chem 2005, 280:34409-34419.

71. Mates AK, Sayed AK, Foster JW: Products of the Escherichia coli acid fitness island attenuate metabolite stress at extremely low $\mathrm{pH}$ and mediate a cell density-dependent acid resistance. J Bacterio/ 2007, 189:2759-2768.

72. Pratt LA, Hsing W, Gibson KE, Silhavy TJ: From acids to osmZ: multiple factors influence synthesis of the OmpF and OmpC porins in Escherichia coli. Mol Microbiol 1996, 20:911-917.

73. Batchelor E, Walthers D, Kenney LJ, Goulian M: The Escherichia coli CpxA-CpxR envelope stress response system regulates expression of the porins OmpF and OmpC. J Bacteriol 2005, 187:5723-5731.

74. Minty JJ, Lesnefsky AA, Lin F, Chen Y, Zaroff TA, Veloso AB, Xie B, McConnell CA, Ward RJ, Schwartz DR: Evolution combined with genomic study elucidates genetic bases of isobutanol tolerance in Escherichia coli. Microb Cell Fact 2011, 10:18.

75. Maciąg A, Peano C, Pietrelli A, Egli T, Bellis GD, Landini P: In vitro transcription profiling of the $\sigma^{5}$ subunit of bacterial RNA polymerase: re-definition of the $\sigma^{S}$ regulon and identification of $\sigma^{\mathrm{S}}$-specific promoter sequence elements. Nucleic Acids Res 2011, 39:5338-5355.

76. Weber H, Polen T, Heuveling J, Wendisch VF, Hengge R: Genome-wide analysis of the general stress response network in Escherichia coli: $\sigma^{S}$. dependent genes, promoters, and sigma factor selectivity. J Bacteriol 2005, 187:1591-1603.

77. Flores N, Escalante A, de Anda R, B\&aacute;ez-Viveros JL, Merino E, Franco B, Georgellis D, Gosset G, Bol\&iacute;var F: New insights into the role of sigma factor RpoS as revealed in Escherichia coli strains lacking the phosphoenolpyruvate: carbohydrate phosphotransferase system. J Mol Microbiol Biotechnol 2008, 14:176-192.

78. Olvera L, Mendoza-Vargas A, Flores N, Olvera M, Sigala JC, Gosset G, Morett E, Bolívar F: Transcription analysis of central metabolism genes in Escherichia coli. Possible roles of $\sigma^{38}$ in their expression, as a response to carbon limitation. PLOS ONE 2009, 4:e7466.

79. Aguilar C, Escalante A, Flores N, de Anda R, Riveros-McKay F, Gosset G, Morett E, Bolívar F: Genetic changes during a laboratory adaptive evolution process that allowed fast growth in glucose to an Escherichia coli strain lacking the major glucose transport system. BMC Genomics 2012, 13:385.

80. Weissbach A, Hurwitz J: The formation of 2-Keto-3-deoxyheptonic acid in extracts of Escherichia coli B. J Biol Chem 1959, 234:705-709.

81. Báez IL, Bolivar F, Gosset G: Determination of 3-deoxy-D-arabino-heptulosonate 7-phosphate productivity and yield from glucose in Escherichia coli devoid of the glucose phosphotransferase transport system. Biotechnol Bioeng 2001, 73:530-535.

82. Muñoz AJ, Hernández-Chávez G, de Anda R, Martínez A, Bolívar F, Gosset G: Metabolic engineering of Escherichia coli for improving L-3,4dihydroxyphenylalanine (L-DOPA) synthesis from glucose. $J$ Ind Microbiol Biotechnol 2011, 38:1845-1852.

\section{doi:10.1186/1475-2859-13-28}

Cite this article as: Cortés-Tolalpa et al:: Global transcriptomic analysis of an engineered Escherichia coli strain lacking the phosphoenolpyruvate: carbohydrate phosphotransferase system during shikimic acid production in rich culture medium. Microbial Cell Factories 2014 13:28.

\section{Submit your next manuscript to BioMed Central and take full advantage of:}

- Convenient online submission

- Thorough peer review

- No space constraints or color figure charges

- Immediate publication on acceptance

- Inclusion in PubMed, CAS, Scopus and Google Scholar

- Research which is freely available for redistribution 